\title{
Cellular survival: a play in three Akts
}

\author{
Sandeep Robert Datta, Anne Brunet, and Michael E. Greenberg ${ }^{1}$ \\ Division of Neuroscience, Children's Hospital and Department of Neurobiology, Harvard Medical School, \\ Boston, MA 02115 USA
}

The programmed cell death that occurs as part of normal mammalian development was first observed nearly a century ago (Collin 1906). It has since been established that approximately half of all neurons in the neuroaxis and $>99.9 \%$ of the total number of cells generated during the course of a human lifetime go on to die through a process of apoptosis (for review, see Datta and Greenberg 1998; Vaux and Korsmeyer 1999/. The induction of developmental cell death is a highly regulated process and can be suppressed by a variety of extracellular stimuli. The purification in the 1950s of the nerve growth factor (NGF), which promotes the survival of sympathetic neurons, set the stage for the discovery that peptide trophic factors promote the survival of a wide variety of cell types in vitro and in vivo (Levi-Montalcini 1987). The profound biological consequences of growth factor (GF) suppression of apoptosis are exemplified by the critical role of target-derived neurotrophins in the survival of neurons and the maintenance of functional neuronal circuits. (Pettmann and Henderson 1998). Recently, the ability of trophic factors to promote survival have been attributed, at least in part, to the phosphatidylinositide 3'-OH kinase (PI3K)/c-Akt kinase cascade. Several targets of the PI3K/c-Akt signaling pathway have been recently identified that may underlie the ability of this regulatory cascade to promote survival. These substrates include two components of the intrinsic cell death machinery, BAD and caspase 9, transcription factors of the forkhead family, and a kinase, IKK, that regulates the NF-кB transcription factor. This article reviews the mechanisms by which survival factors regulate the PI3K/c-Akt cascade, the evidence that activation of the $\mathrm{PI} 3 \mathrm{~K} / \mathrm{c}-\mathrm{Akt}$ pathway promotes cell survival, and the current spectrum of c-Akt targets and their roles in mediating c-Akt-dependent cell survival.

\section{Setting the stage: PI3K mediates survival signals}

PI3K and cell survival

Recent data have implicated PI3 kinases and their phospholipid products in promoting survival downstream of extracellular stimuli. Survival stimuli generally mediate intracellular signaling through ligation of transmembrane receptors, which either possess intrinsic tyrosine kinase activity (e.g., the insulin-like growth factor I re-

${ }^{1}$ Corresponding author.

E-MAIL greenberg@a1.tch.harvard.edu; FAX (617) 738-1542. ceptor), are indirectly coupled to tyrosine kinases (e.g., integrins), or are coupled to seven transmembrane $\mathrm{G}$ protein-coupled receptors (e.g., the lysophosphatidic acid receptor $\mathrm{LP}_{\mathrm{A} 1} / \mathrm{VZG}-1$ ) (Clark and Brugge 1995; Segal and Greenberg 1996; Weiner and Chun 1999). Activation of these receptors results in the recruitment of PI3K isoforms to the inner surface of the plasma membrane as a result of ligand-regulated protein-protein interactions (for review, see Toker and Cantley 1997; Rameh and Cantley 1999). PI3K can also be activated by direct interaction with the Ras protooncogene (Rodriguez-Vicana et al. 1994, 1996; Marte et al. 1996; Kauffmann-Zeh et al. 1997; Khwaja et al. 1997; Liu et al. 1998; Murga et al. 1998). Once localized to the plasma membrane, PI3Ks catalyze the transfer of phosphate from ATP to the D-3 position of the inositol ring of membrane-localized phosphoinositides, thereby generating 3 '-phosphorylated phosphoinositides. The major isoforms of PI3K that are activated in response to receptor-mediated survival signals principally generate phosphatidylinositol 3,4 bisphosphate $(\mathrm{PI} 3,4 \mathrm{P})$ and phosphatidylinositol 3,4,5 trisphosphate $(\mathrm{PI} 3,4,5 \mathrm{P})$. Once generated, these lipids then function as signaling intermediates that regulate downstream signal transduction cascades.

PI3K was first implicated in the suppression of apoptosis in a study by Yao and Cooper (1995) in which the signal transduction pathways that control GF-mediated survival of the pheochromocytoma cell line PC12 were investigated. This study demonstrated that inhibition of PI3K activity abrogated the ability of NGF to promote cell survival. In addition, when cells were transfected with PDGF receptor (PDGFR) mutants in which the specific tyrosine residues critical for activating particular signaling pathways were mutated, it was found that the PDGFR tyrosine residues that bind to and activate PI3K were both necessary and sufficient for the PDGF-mediated survival of these cells.

PI3K activity was subsequently found to be required for the GF-dependent survival of a wide variety of cultured cell types ranging from fibroblasts to neurons (Scheid et al. 1995; Yao and Cooper 1995; Takashima et al. 1996; Vemuri and McMorris 1996; Dudek et al. 1997; Kauffmann-Zeh et al. 1997; Khwaja et al. 1997; Philpott et al. 1997; Berra et al. 1998; Crowder and Freeman 1998; Stambolic et al. 1998; Ulrich et al. 1998; Weiner and Chun 1999; Fruman et al. 1999). PI3K activity is also sufficient to promote cellular survival in the absence of trophic support and to block apoptosis induced by toxic 
stimuli. GF-deprived cells that are transfected with constitutively active PI3K alleles, with receptor mutants in which PI3K is exclusively activated in response to receptor ligation, or with constitutively active Ras mutants that bind to and activate only PI3K are, in each case, resistant to apoptosis. (Yao and Cooper 1995; Kauffmann-Zeh et al. 1997; Khwaja and Downward 1997; Khwaja et al. 1997; Kulik et al. 1997; Philpott et al. 1997; Chen et al. 1998; Crowder and Freeman 1998; Ulrich et al. 1998).

Whereas increases in PI3K activity may be sufficient and frequently necessary to promote cell survival in response to GFs, the existence of parallel survival pathways emanating from RTKs has challenged the idea that there is an absolute requirement for PI3K activity for cellular survival. Several studies have suggested that Ras and its downstream effectors Raf-MEK-MAPK are critical mediators of GF-induced survival in a number of different cell types (Borasio et al. 1989, 1993; Nobes and Tolkovsky 1995). It is now clear that the Raf-MEKMAPK cascade does under some circumstances promote cell survival (Xia et al. 1995; Parrizas et al. 1997; Bergmann et al. 1998; Kurada and White 1998; Meier and Evan 1998; Anderson and Tolkovsky 1999; Bonni et al. 1999; Shimamura et al. 1999|. However, Ras-dependent cell survival is likely mediated both by the Raf-MEKMAPK pathway and Ras-mediated activation of PI3K. Thus, PI3K is a major effector pathway mediating survival signals downstream of survival factors, either through direct activation of PI3K by growth factor receptors, or through intermediate activation of Ras (Rodriguez-Vicana et al. 1994, 1996).

\section{3'-phosphorylated phosphoinositides and survival}

Additional evidence of a role for the products of PI3K in survival signaling comes from studies of the PTEN tumor suppressor. PTEN is a lipid phosphatase that dephosphorylates PI3K-generated 3'-phosphorylated phosphatidylinositides in vivo ( $\mathrm{Gu}$ et al. 1998; Maehama and Dixon 1998; Myers et al. 1998; Stambolic et al. 1998). Overexpression of PTEN is sufficient to lower basal 3'-phosphorylated phosphoinositide levels in cells. PTEN ${ }^{-/-}$mice have elevated levels of 3 '-phosphorylated phospholipids and die during embryogenesis as a result of a failure in developmental apoptosis (Stambolic et al. 1998; Suzuki et al. 1998). PTEN ${ }^{-/-}$mouse embryo fibroblasts (MEFs) are resistant to a range of apoptotic stimuli, suggesting that the cell survival phenotype observed in these animals may reflect a specific cellular resistance to developmental and pathologic apoptosis. Such resistance to apoptosis is likely due to an elevation in the basal level of $3^{\prime}$-phosphorylated phosphatidylinositides, as pharmacologic inhibition of PI3K activity renders these cells susceptible to toxicity-induced apoptosis.

Only a subset of the lipid products generated by PI3K may be capable of promoting cell survival in certain cell types. Evidence consistent with this idea has come from studies utilizing $\mathrm{SHIP}^{-/-}$animals (Helgason et al. 1998;
Liu et al. 1999). SHIP is a lipid phosphatase that dephosphorylates phosphatidylinositides at the $5^{\prime}$ position. Deletion of SHIP leads to a relative increase in PI3,4,5P levels and a corresponding decrease in the levels of $\mathrm{PI}, 4 \mathrm{P}$. SHIP $\mathrm{P}^{-/-}$mice demonstrate defects in executing apoptosis and excessive cellular survival in myeloid lineages, suggesting that $\mathrm{PI}, 4,5 \mathrm{P}$ as opposed to $\mathrm{PI}, 4, \mathrm{P}$ is required for cell survival. Consistent with this idea, overexpression of SHIP is sufficient to induce apoptosis in hematopoietic cells (Liu et al. 1997; Aman et al. 1998) Thus, in some cell types PI3,4,5P may mediate the antiapoptotic effect of PI3K, although based on the ability of both $\mathrm{PI}, 4,5 \mathrm{P}$ and $\mathrm{PI}, 4 \mathrm{P}$ to regulate signaling downstream of PI3K (see below) it is likely that both lipid products contribute to cellular survival.

\section{Act 1: Akt is a general mediator of survival signals}

Given the importance of PI3K as a mediator of GF-regulated survival signals, there has been significant interest in identifying the molecular targets of PI3K that block apoptosis. 3'-phosphorylated phospholipids are capable of activating a number of cellular intermediates, including tyrosine kinases, GTPase activating proteins for small $\mathrm{G}$ proteins, and a variety of serine/threonine protein kinases such as the atypical PKC isoforms, SGK, the pp70 ${ }^{\text {S6K }}$, and c-Akt (Rameh and Cantley 1999). A number of these targets of PI3K have been implicated in the suppression of apoptosis (Diaz-Meco et al. 1996; Nishida et al. 1998). However, recent data suggesting that c-Akt activity is sufficient to block apoptosis induced by a number of death stimuli, and that c-Akt activity is required for GF-mediated survival, has focused attention on the role of c-Akt as a mediator of the PI3K survival signal.

\section{Akt structure}

c-Akt is the cellular homolog of the transforming oncogene of the AKT8 retrovirus (Staal 1987; Staal et al. 1977; Bellacosa et al. 1991, 1993). Molecular analysis revealed that $v$-akt resulted from a recombination event between viral gag sequences and the cellular Akt gene, resulting in a gag-c-Akt fusion protein. Simultaneous with the identification of c-Akt, the protein kinase $\mathrm{B} \alpha$ and Related to A- and C-Protein Kinase $\alpha$ were cloned in screens to identify proteins with kinase domains to that within PKA and PKC (Coffer and Woodgett 1991; Jones et al. 1991). c-Akt1, PKB $\alpha$ and RAC-PK $\alpha$ were found to be encoded by the same gene (herein referred to as Akt). Two additional Akt family members have also been identified, c-Akt2/PKB $\beta /$ RAC-PK $\beta$ and c-Akt3/RACPK $\gamma$ (Staal et al. 1987; Cheng et al. 1996; Konishi et al. 1995; Brodbeck et al. 1999; Nakatani et al. 1999). The three known mammalian Akt family members are expressed differentially at both the mRNA and protein levels (Bellacosa et al. 1993; Altomare et al. 1995, 1998; Brodbeck et al. 1999). Akt orthologs have been cloned from a number of species, including Drosophila melanogaster and Caenorhabditis elegans (Fig. 1) (Franke et al. 1994; Paradis and Ruvkun 1998). 
Akt family proteins contain a central kinase domain with specificity for serine or threonine residues in substrate proteins (Fig. 1) (Bellacosa et al. 1991; Coffer and Woodgett 1991). In addition, the amino terminus of Akt includes a pleckstrin homology $(\mathrm{PH})$ domain, which mediates lipid-protein and/or protein-protein interactions (Mayer et al. 1993; Musacchio et al. 1993; Datta et al. 1995). The Akt carboxyl terminus includes a hydrophobic and proline-rich domain. Alignment of Akt family members suggests that the primary structure of Akt is conserved across evolution, with the exception of the carboxy-terminal tail, which is found in some but not all species and isoforms.

\section{Upstream regulation of Akt kinase activity}

Akt was first implicated in signal transduction by the demonstration that the kinase activity of Akt is induced by GFs such as PDGF and basic fibroblast growth factor (bFGF) (Burgering and Coffer 1995; Franke et al. 1995). It is now known that a diverse array of physiologic stimuli are capable of inducing Akt kinase activity by up to 40fold (Table 1), primarily in a PI3K-dependent manner.

PI3K-generated phospholipids act by multiple mechanisms that cooperate to regulate Akt activity. One mechanism is through the direct binding of phosphoinositides to the Akt PH domain (James et al. 1996; Franke et al. 1997; Frech et al. 1997). The binding of PI3K-generated phospholipids to Akt in vivo has been shown to be critical to the activation of Akt (Franke et al. 1995, 1997; Klippel et al. 1997; Bellacosa et al. 1998; Sable et al. 1998). A consequence of Akt binding to phospholipids is the translocation of Akt from the cytoplasm to the inner surface of the plasma membrane, where PI3K-generated 3'-phosphorylated phospholipids reside (Andjelkovic et al. 1997; Meier et al. 1997; Wijkander et al. 1997; Zhang and Vik 1997; Sable et al. 1998; Currie et al. 1999|. This translocation is important for Akt activation. Indeed, v-Akt, which is permanently targeted to the plasma membrane by the viral gag sequence, exhibits constitutive kinase activity (Franke et al. 1995). Likewise, c-Akt is constitutively active when specifically targeted to the inner surface of the plasma membrane (Burgering and Coffer 1995; Kohn et al. 1996a). These findings suggest that the relocalization of Akt to the plasma membrane is an important step in the process of Akt activation.

Relocalization of Akt to the plasma membrane brings Akt in proximity to regulatory kinases that phosphorylate and activate Akt. The existence of such kinases was suggested by experiments demonstrating that Akt itself is a phosphoprotein, and that phosphorylation is required for Akt activity in vivo and in vitro. (Bellacosa et al. 1991; Coffer and Woodgett 1991; Burgering and Coffer 1995; Anjelkovic et al. 1996; Kohn et al. 1996b; Soskic et al. 1999). Alessi and colleagues (Alessi et al. 1996a) identified four sites (Ser-124, Thr-308, Thr-450, and Ser-473) on Akt1 that are phosphorylated in vivo. Thr-308 and Ser-473 are inducibly phosphorylated after treatment of cells with extracellular stimuli, whereas Ser-124 and Thr-450 appear to be basally phosphorylated. Mutagenesis studies have revealed that phosphorylation of Thr308 and Ser-473 is required for Akt activity, and that mimicking phosphorylation partially activates Akt. Akt Thr-308 lies within the Akt kinase domain activation loop, a region that when unphosphorylated negatively regulates the kinase activity of Akt. Thus, phosphorylation of Akt Thr-308 has emerged as an attractive mechanism by which upstream kinases may induce Akt activity.

Four distinct biochemical entities have been identified that are capable of phosphorylating Akt at Thr-308 in the presence of PI3,4,5P (Alessi et al. 1997b; Stokoe et al. 1997). These protein kinases are also capable of inducing the kinase activity of Akt towards an in vitro substrate in a PI3,4,5P dependent-manner. Because these kinases display lipid dependence for their activation, they were termed 3-phosphoinositide-dependent protein kinases (PDKs). PDK-1 and PDK-a, which are likely the protein products of the same gene, were cloned based on peptide sequencing of the PDK fractions (Alessi et al. 1997b; Stephens et al. 1998). The PDK-1 cDNA encodes a $63-\mathrm{kD}$ protein that contains a $\mathrm{PH}$ domain and a consensus kinase domain closely related to that of PKA, Akt, and PKC (Alessi et al. 1997b; Hanks et al. 1988).

PDK-1 efficiently phosphorylates Akt at Thr-308, and overexpression of PDK-1 is sufficient to activate Akt in transfected cells (Alessi et al. 1997a). However, unlike Akt, PDK-1 is a constitutively active enzyme, and its kinase activity within cells does not appear to be enhanced by the presence of survival factors that activate

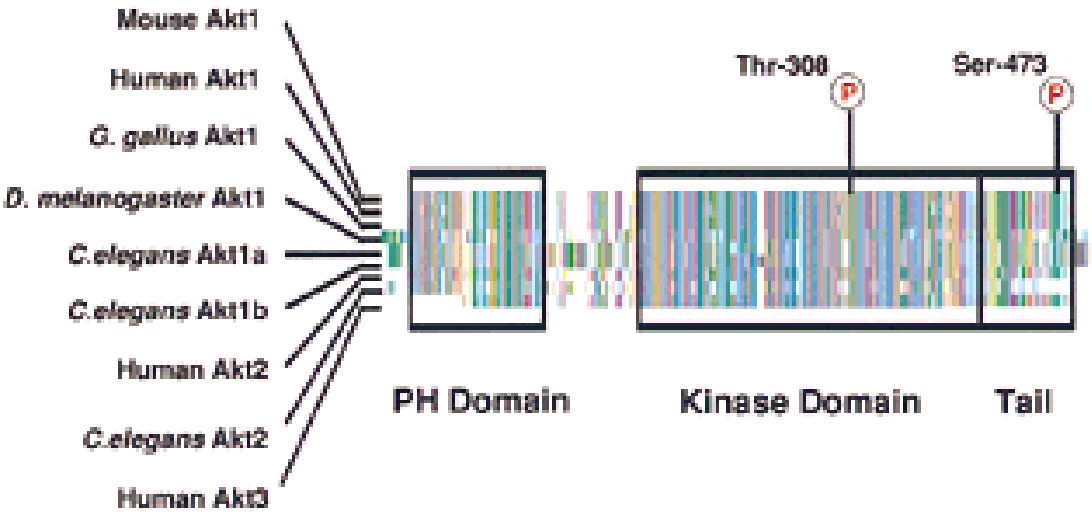

Figure 1. Multiple sequence alignment and domain structure of selected isoforms of Akt. Aligned vertically colored stripes represent amino acid similarity. The absence of color indicates either sequence gaps or degenerate sequence. Note the absolute conservation of the regulatory phosphorylation sites equivalent to Thr-308, and the similar conservation of the sites similar to Ser-473 in all isoforms except C. elegans Akt2. 
Table 1. Stimuli that induce increased Akt kinase activity

\begin{tabular}{l}
\hline Stimuli that regulate tyrosine kinase activity \\
Angiopoietin-1 \\
Anti-CD28 Abs \\
Epidermal growth factor \\
Basic fibroblast growth factor \\
Fibronectin \\
Gas6 \\
Anti-integrin antibodies \\
Interleukin-2 \\
Interleukin-3 \\
Interleukin-4 \\
Interleukin-5 \\
Interleukin-8 \\
Insulin \\
Insulin-like growth factor \\
Anti-killer cell inhibitory receptor antibodies \\
Leukemia inhibitory factor \\
Nerve growth factor \\
Platelet-derived growth factor \\
Stem cell factor \\
Vascular endothelial growth factor \\
Stimuli that regulate G-protein-linked receptors \\
C5a \\
Carbachol \\
GRO $\alpha$ \\
fMet-Leu-Pro \\
$\mu$ Opiods \\
Platelet Activating Factor \\
RANTES \\
cAMP/PKA agonists \\
CPT-cAMP \\
Forskolin \\
8-Br-cAMP \\
Isoproteronol \\
Phosphatase inhibitors \\
Vanadate \\
Peroxyvanadate \\
Okadaic acid \\
Other activators \\
Hypoxia \\
SNP (NO donor) \\
Exercise \\
\hline
\end{tabular}

Akt (Alessi et al. 1997a). In unstimulated cells, PDK-1 is located in both the cytoplasm and at the inner surface of the plasma membrane (Currie et al. 1999). Although some data suggest that PDK-1 translocates to the plasma membrane in response to GF stimulation, electron microscopy analysis indicates that the subcellular localization of PDK-1 does not change significantly in response to extracellular stimuli (Anderson et al. 1998a; Currie et al. 1999). On its own, PDK-1 is incapable of phosphorylating Akt at Ser-473 (Alessi et al. 1997b,c; Stokoe et al.
1997). However, it has recently been suggested that the functional characteristics of PDK-1 are modified in vivo when PDK-1 interacts with other proteins. PDK-1 may complex with a fragment of another kinase, PRK-2 (Balendran et al. 1999). Unlike PDK-1 alone, the PDK-1/ PRK-2 complex is capable of phosphorylating Akt at both Thr-308 and Ser-473. In addition, the activity of the PDK-1/PRK-2 complex is upregulated by PI3K-generated 3 '-phosphorylated phospholipids. The responsiveness of PDK-1/PRK-2 complex to phospholipids may be due to the ability of the PH domain of PDK-1 to directly bind to 3'-phosphorylated phosphoinositides with high affinity (Currie et al. 1999). Thus the second mechanism by which phospholipids regulate Akt is by regulating the activity of kinases, such as the PDK-1/PRK-2 complex, that modulate Akt activity.

Integrin-linked kinase (ILK), a serine/threonine kinase that interacts with the cytoplasmic tail of integrin $\beta$ subunits (Delcommenne et al. 1998), has also been suggested to regulate Akt by phosphorylation of Akt at Ser473. ILK is directly regulated by PI3,4,5P, presumably through binding of lipids to a cryptic PH domain within ILK. Further studies are required to determine whether ILK activity is sufficient to activate Akt in vitro and if ILK is an Akt Ser-473 kinase within cells.

The third mechanism by which 3'-phosphorylated phosphoinositides regulate Akt activity is by controlling the accessibility of Akt as a substrate for PDKs. In in vitro reconstitution assays, the binding of PI3,4,5P to the Akt $\mathrm{PH}$ domain is required for PDK-1 to phosphorylate Akt (Alessi et al. 1997b,c; Stokoe et al. 1997; Bellacosa et al. 1998; Currie et al. 1999). Mutations in the Akt PH domain that abrogate phospholipid binding also block PDK-1 phosphorylation of Akt. Conversely, mutations in the Akt PH domain that enhance lipid binding reduce the concentration of PI3,4,5P that is required for PDK-1 to phosphorylate Akt. In addition, PDK-1 is capable of effectively phosphorylating Akt in the absence of phospholipids when the Akt PH domain is deleted. These results are consistent with the possibility that the binding of phospholipids to the Akt $\mathrm{PH}$ domain induces a critical conformational change that renders Akt competent for phosphorylation by PDKs.

Phospholipid binding may also act through additional mechanisms to regulate Akt activity. For example, the binding of 3'-phosphorylated phospholipids by the Akt $\mathrm{PH}$ domain may result in a conformational change that increases the intrinsic catalytic activity of Akt (Datta et al. 1996; James et al. 1996; Franke et al. 1997; Frech et al. 1997; Klippel et al. 1997). Lipid binding also induces the formation of Akt homomultimers, which may increase Akt activity (Datta et al. 1995; Franke et al. 1997; Alberti 1998). The relevance of these mechanisms to Akt activation in vivo remains to be demonstrated.

\section{A model for Akt activation}

Efforts to elucidate the mechanism of by which GFs regulate Akt activity have led to a complex picture of 
how phospholipids and PDK-1 cooperate to achieve the activation of Akt (Fig. 2). Phosphorylation of Akt at Ser124 and Thr-450 occurs independently of cell stimulation or PI3K activation, and most likely renders Akt competent to undergo activation upon exposure of cells to extracellular stimuli (Fig. 2A). GF stimulation of PI3K leads to increased intracellular levels of PI3,4P and PI3,4,5P. Binding of the these lipids to the Akt PH domain results in Akt translocation from the cytoplasm to the plasma membrane; in addition, the interaction of the $\mathrm{PH}$ domain with the lipid products of PI3K causes a conformational change in Akt that renders Akt accessible to phosphorylation at Thr-308 and Ser-473. (Fig. 2B). Phospholipids also increase the ability of the PDK-1-which may be complexed with PRK-2, a fragment of PRK-2, or other related proteins-to phosphorylate Akt. The final step in Akt activation appears to be the phosphorylation of Thr-308 and Ser-473 by PDK-1 (Fig. 2C,D).

There are also survival stimuli that activate Akt via mechanisms that do not require stimulation of PI3K. Agonists of the PKA pathway can activate Akt (Sable et al. 1997; Filippa et al. 1999) as can increases in cytoplasmic calcium levels. Calcium binds to calmodulin, and the $\mathrm{Ca} 2+$ /calmodulin complex activates the calcium/ calmodulin dependent kinase kinase (CaMKK), which then activates Akt by directly phosphorylating Akt at Thr-308 (Yano et al. 1998). Thus, under some circumstances kinases related to PDK-1 can substitute for PDK-1 in activating Akt.

\section{Akt activity is both necessary and sufficient for survival}

The observation that Akt is a target of PI3K, together with the finding that PI3K mediates GF-dependent survival, suggested that Akt might be a critical regulator of cell survival. This possibility was first tested in a study of the signaling molecules utilized by IGF-1 and PI3K to promote the survival of cultured cerebellar granule cells (Dudek et al. 1997). Transfection of granule cells with dominant-negative Akt alleles abrogated the ability of IGF-1 to promote the survival of these cells. Conversely, transfection with either wild-type Akt or constitutively active Akt alleles promoted the survival of these cells, even in the absence of IGF-1.

A large number of studies have demonstrated that transfection of a variety of cell types with constitutively active Akt alleles (and in some cases wild-type Akt) blocks apoptosis induced by apoptotic stimuli, including GF withdrawal, UV irradiation, matrix detachment, cell cycle discordance, DNA damage, and treatment of cells with anti-Fas antibody or TGFß (Dudek et al. 1997; Kauffmann-Zeh et al. 1997; Kennedy et al. 1997; Khwaja and Downward 1997; Khwaja et al. 1997; Kulik et al. 1997; Philpott et al. 1997; Songyang et al. 1997; Xiong and Parsons 1997; Chen et al. 1998; Crowder and Freeman 1998; Eves et al. 1998; Gerber et al. 1998; Hausler et al. 1998; Kulik and Weber 1998; Rohn et al. 1998; Blair et al. 1999). The possibility that GF-mediated survival requires Akt has been explored using dominant-negative alleles of Akt, either catalytically inactive Akt (Dudek et al. 1997; Kitamura et al. 1998a; van Weeren et al. 1998) or a mutant Akt consisting only of the $\mathrm{PH}$ domain (Songyang et al. 1997). Expression of either of these Akt alleles has been found to block the ability of a variety of growth factors to promote survival (Dudek et al. 1997; Kennedy et al. 1997; Khwaja et al. 1997; Kulik et al. 1997; Songyang et al. 1997; Berra et al. 1998; Chen et al. 1998; Crowder and Freeman 1998; Gerber et al. 1998; Kulik and Weber 1998; Yano et al. 1998; Weiner and Chun 1999). Two additional dominant-negative Akt alleles have been generated recently, the first a wild-type Akt that is fused to the Ras CAAX membrane targeting sequence (CAAX-Akt), and the second an Akt with
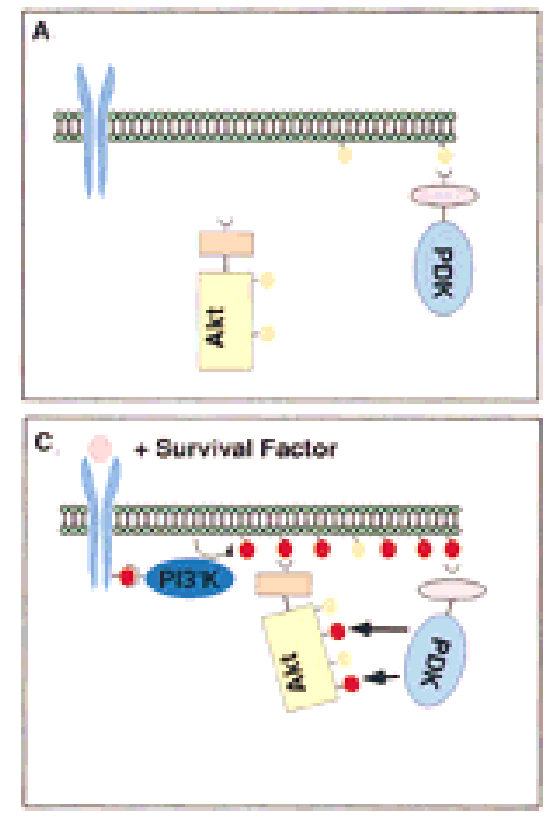
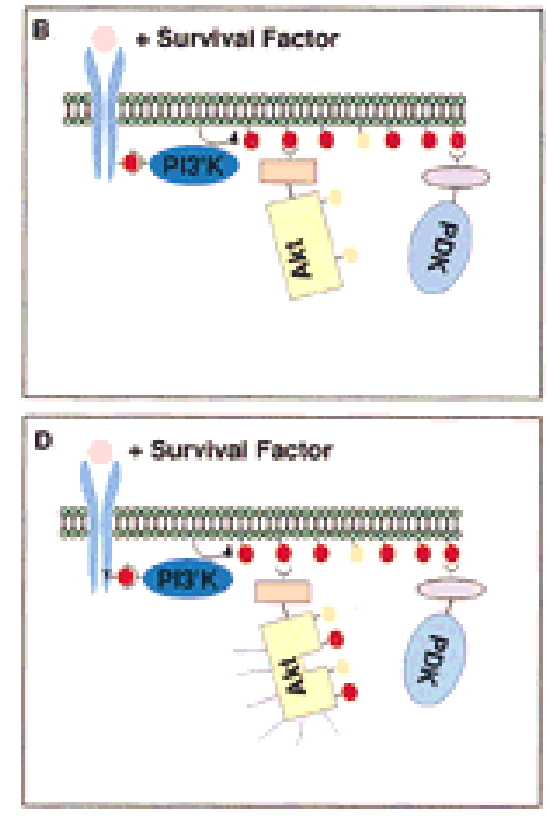

Figure 2. Model for the survival factor-mediated activation of Akt. $(A)$ In unstimulated cells, Akt is basally phosphorylated at Ser-124 and Thr-450 (peach circles). PDKs are partially localized to the plasma membrane. $(B)$ Growth factor-mediated PI3K activation results in increases in $3^{\prime}$-phosphorylated phosphoinositides (red circles), which results in both the translocation of Akt to the plasma membrane and a conformational change that renders the regulatory phosphorylation sites accessible to PDKs. In addition, PDK-1 complexed with either a fragment of PRK2, PRK2, or a PRK2-related peptide may be regulated by increased phospholipid concentrations. $(C, D)$ The PDK1/PRK complex phosphorylates Akt at Thr-308 and Ser-473, resulting in Akt activation. 
its PDK phosphorylation sites mutated to alanine (AktTASA). Although the mechanism by which either CAAX-Akt or AktTASA inhibits the function of endogenous Akt is not clear, both CAAX-Akt and AktTASA effectively block cellular survival (Rohn et al. 1998; Stambolic et al. 1998).

The use of dominant-negative Akt alleles has been controversial, both because of their potential lack of specificity and because of the apparent lack of inhibition of endogenous Akt activity by some dominant-negative Akt mutants. However, it is possible that dominantnegative Akt mutants act by directly interacting with specific downstream targets of Akt. Genetic studies from Drosophila have also recently provided independent confirmation for a role for Akt in cell survival. Flies defective in dAKT1 show significant ectopic apoptosis during embryogenesis (Stavely et al. 1998). Indirect biological evidence also suggests that Akt activity is crucial to promoting cellular survival. For example, treatment of cells with ceramide, a critical lipid intermediate that is involved in death signals (for review, see Basu and Kolesnick 1998), is sufficient to block Akt activity in a number of cell types (Summers et al. 1998; Zhou et al. 1998; Zundel and Giaccia 1998). Akt has also been shown to be selectively proteolysed during the early stages of apoptosis (Widmann et al. 1998). These data suggest that an important feature of the initiation of programmed cell death is the downregulation of Akt activity. Taken with data demonstrating that Akt activity under certain circumstances is both necessary and sufficient for cell survival, these experiments support the hypothesis that Akt is a crucial mediator of survival signals.

\section{Akt, survival, and oncogenesis}

The identification of Akt as a key regulator of cellular survival has significant implications for current models of oncogenesis. A number of oncogenes and tumor suppressor genes that function upstream of Akt have been found to influence cancer progression by regulating Akt. PI3K has been identified as the enzymatic component of the naturally occurring oncogene vP3K; cells transformed by vP3K exhibit constitutive Akt activation, and transfection of such cells with dominant-negative Akt alleles can revert oncogenic transformation (Chang et al. 1997; Aoki et al. 1998). Oncoproteins that act in part through increasing PI3K activity, including activated Ras and Bcr/Abl, may also require Akt activation to promote oncogenesis. For example, cotransfection of bone marrow precursors with kinase-inactive Akt suppresses the ability of wild-type $\mathrm{Bcr} / \mathrm{Abl}$ to promote leukemogenesis in vivo (Skorski et al. 1997). PTEN has also been identified as a human tumor suppressor whose loss correlates with increased Akt activity (Li et al. 1997; Liaw et al. 1997; Nelen et al. 1997; Marsh et al. 1998; Cantley and Neel 1999). Overexpression of wild-type Akt may also cause oncogenesis, as Akt2 has been found to be amplified with high frequency in pancreatic, breast, and ovarian tumors (Bellacosa et al. 1995; Cheng et al. 1996).
It is important to note that suppression of apoptosis is not the only function that Akt may play in promoting oncogenesis, as Akt under some circumstances, can induce cell cycle progression (Ahmed et al. 1997; Brennan et al. 1997). However, the observation that Akt can suppress apoptosis, taken with the finding that deletion of PTEN, overexpression of active Ras, or overexpression of active PI3K renders cells resistant to apoptosis, suggests that oncogenes may block adaptive cellular apoptosis by hyperactivating Akt.

\section{Act 2: Akt targets in cell survival-the apoptotic machinery}

The search for substrates of Akt that are relevant to the survival-promoting effects of Akt has been significantly aided by the definition of a consensus sequence of the preferred Akt in vitro phosphorylation sites (Alessi et al. 1996b; Walker et al. 1998). Protein database analysis reveals a large number of mammalian proteins that contain Akt consensus phosphorylation sites (RXRXXS/Tbulky hydrophobic). Among these proteins are several components of the apoptotic machinery (Table 2). However, an important caveat to such database searches is the likelihood that in vivo the substrate specificity of Akt will partially depend on sequence determinants that lie outside the RXRXXS/T consensus.

The identification of the Akt consensus phosphorylation sequence in proteins involved in the apoptotic process raised the possibility that Akt regulates cell survival by directly phosphorylating components of the cell death apparatus. Because of the explosion of information regarding the molecular components of the mammalian apoptotic machinery and their complex interrelationships, we will provide only a brief synopsis of the death mechanisms that are relevant to GF withdrawal-induced apoptosis and Akt-mediated suppression of this process.

The basis for the current understanding of mammalian apoptosis comes in large part from genetic studies in $C$. elegans in which a series of genes have been identified that control developmental cell death (for review, see Horvitz 1999). The C. elegans ced-9 and egl-1 are related to mammalian $B c l-2$, which was first identified as an oncogene generated as part of a $\mathrm{t}(14: 18)$ translocation in follicular lymphomas. Bcl-2 is the prototype for a large family of structurally related proteins that regulate cell death in mammalian cells (for review, see Reed 1998; Green and Reed 1998). Some of these proteins, such as Bcl-2 and Bcl- $\mathrm{X}_{\mathrm{L}}$, promote cell survival whereas other proteins in this family, such as Bax and Bad, promote cell death. The activity of Bcl-2 family members is regulated in part through their ability to form homo- and heterodimers. The various Bcl-2 family members are part of a network of apoptotic regulators that are located both in the cytoplasm and at intracellular membranes, including the outer mitochondrial membrane. In the presence of survival factors, the activity of prosurvival Bcl-2 family members prevails over the activity of prodeath Bcl-2 family members. Withdrawal of trophic support causes, through transcription-dependent and -indepen- 
Table 2. Proteins that are components of the apoptotic machinery that contain the Akt consensus phosphorylation site

\begin{tabular}{|c|c|c|c|}
\hline Member of the apoptotic machinery & \multicolumn{2}{|c|}{ Akt potential phosphorylation sites } & Species \\
\hline \multicolumn{4}{|l|}{ Ced-9/Bcl-2 family member } \\
\hline $\mathrm{BAD}$ & $\underline{R} S \underline{R} H S S Y$ & $\underline{R G R S R S A}$ & human/mouse/rat \\
\hline Harakiri & $\underline{R} R \underline{R} A R S R$ & & human (not present in mouse or rat) \\
\hline Bcl-2 & $\underline{\bar{R}} G \underline{\bar{R}} F A T V$ & & human/mouse/rat \\
\hline \multicolumn{4}{|l|}{ Ced-4 homologs } \\
\hline Apaf1 & $\underline{\text { RIRKSSS }}$ & & human/mouse \\
\hline FLASH & $\overline{\mathrm{R}} \overline{\mathrm{GRSGTR}}$ & RERPHTR & mouse \\
\hline \multicolumn{4}{|l|}{ Ced-3/caspases } \\
\hline Caspase 9/ICE LAP6 & $\underline{\text { RTRTGSN }}$ & $\underline{R R} \underline{R F S S L}$ & human \\
\hline Caspase 8/FLICE & RDRNTH & & human \\
\hline Caspase 7 & $\underline{\mathrm{R}} \mathrm{D} \mathrm{R} V \mathrm{TY}$ & & human/mouse/rat \\
\hline \multicolumn{4}{|l|}{ Caspase inhibitors } \\
\hline IAP & RLRTFTE & & baculovirus \\
\hline D-IAP1 & $\underline{\bar{R}} \underline{\bar{R}} \mathrm{CFSC}$ & & fly \\
\hline IAP-3/X-IAP & $\underline{\mathrm{R}} \mathrm{H} \underline{\mathrm{R}}(\mathrm{K} / \mathrm{R})(\mathrm{V}$ & & human/mouse \\
\hline
\end{tabular}

These proteins were identified from the SWISS-PROT database using the ScanPrositeTool algorithm with the sequence R-X-R-X-X$(\mathrm{S} / \mathrm{T})-\mathrm{X}$. These proteins represent a small subset of the $>10,000$ peptides containing the query sequence contained in the database.

dent mechanisms, a change in the balance between prosurvival and prodeath Bcl-2 family members. This disequilibrium results in the translocation of pro-apoptotic Bcl-2 family members from the cytoplasm to the mitochondrial outer membrane. Prodeath Bcl-2 family members then initiate a cell death program, which involves changes in the mitochondria that includes the opening of the permeability transition pore (PTP), decreases in the mitochondrial membrane potential, decreases in nucleotide exchange, and the release of cytochrome $\mathrm{C}$ into the cytoplasm.

Increases in the concentration of cytochrome $\mathrm{C}$ in the cytoplasm result in the nucleation of a multiprotein complex known as the apoptosome (for review, see Tsujimoto 1998). The apoptosome is comprised of the Apaf-1 adapter protein, cytochrome $\mathrm{C}$, dATP, and the aspartyldirected protease caspase 9. Caspase 9 and Apaf- 1 are the mammalian homologs of that nematode genes ced-3 and ced-4, respectively. Mutations in ced-3 or ced-4 cause decreased cell death in the worm. In mammalian cells, cytochrome $\mathrm{C}$ binds to Apaf-1, releasing an intramolecular inhibition and facilitating an interaction between Apaf-1 and caspase 9. This interaction, in turn, activates the proteolytic activity of caspase 9. The substrate specificities of the caspases orders them in a hierarchical fashion, such that initiator caspases (such as caspase 9) activate through cleavage downstream effector caspases (such as caspases 3 and 7) (for review, see Cryns and Yuan 1998). These effector caspases cleave a variety of cellular substrates that are critical to the generation of the apoptotic phenotype.

In addition to the ability of Bcl-2 family members to indirectly regulate the apoptosome through control of cytochrome C release, Bcl-2 family members may directly regulate the apoptosome by binding to Apaf- 1 (for review, see Dragovich et al. 1998). Bcl- $\mathrm{X}_{\mathrm{L}}$ can bind to Apaf- 1 and can block the ability of Apaf- 1 to activate procaspase 9; the binding of Bcl- $\mathrm{X}_{\mathrm{L}}$ to Apaf-1 is antagonized by Bax. Therefore, the Bcl-2 family regulates apop- tosis both upstream and downstream of mitochondrial cytochrome C release. Prodeath Bcl-2 family members that are activated upon GF withdrawal can also induce cell death independently of protease activation, although the mechanism by which this occurs is not yet understood.

In some cell types, GF withdrawal triggers cell death in part through a mechanism that is initiated at the plasma membrane and involves the activation of cell surface death receptors (Le-Niculescu et al. 1999). Activation of these receptors, which act through adapter proteins such as FADD, results in the activation of caspase 8 (for review, see Green 1998). Caspase 8 is itself capable of activating caspase 3 and initiating apoptosis independently of the apoptosome, although in some cell types cytochrome $\mathrm{C}$ release and apoptosome activation are required for efficient death by this alternate pathway.

Given the complexity of the apoptotic machinery, there are a number of points at which Akt might act to promote survival and inhibit death. Akt may block apoptosis by regulating the expression or activity of prosurvival and prodeath Bcl-2 family members; the caspase family of proteins; or the function of death receptor pathways. Akt may control these regulatory points either directly by phosphorylating components of the apoptotic machinery or indirectly by changing the levels of expression of genes that encode components of the death machinery. Recent studies have demonstrated that Akt regulates apoptosis at multiple sites, and has identified direct Akt targets including Bad, caspase 9, the Forkhead family of transcription factors (discussed below), and the NF- $\mathrm{kB}$ regulator IKK, each of which plays a critical role in mediating cell death.

\section{Bad}

The first component of the apoptotic machinery found to be phosphorylated by Akt was the Bcl-2 family member Bad. Bad was identified on the basis of its ability to bind to Bcl-2, and analysis of its primary structure reveals that 
Bad is similar to Bcl-2 exclusively within its BH3 domain (Yang et al. 1995). Bad directly interacts via its BH3 domain with prosurvival Bcl-2 family members such as Bcl- $\mathrm{X}_{\mathrm{L}}$, and when overexpressed blocks Bcl- $\mathrm{X}_{\mathrm{L}}$-dependent cell survival (Yang et al. 1995; Ottilie et al. 1997; Zha et al. 1997). Disruption of the Bad BH3 domain by a point mutation or deletion abrogates the ability of Bad, both to interact with $\mathrm{Bcl}-\mathrm{X}_{\mathrm{L}}$ and to induce cell death.

Korsmeyer and colleagues demonstrated that the activity of Bad was modulated by the addition of growth factors to GF-deprived cells (Zha et al. 1996). In the absence of survival factors, Bad is phosphorylated and associates with Bcl- $\mathrm{X}_{\mathrm{L}}$. The exposure of cell lines to GFs induces the phosphorylation of Bad at two sites, Ser-112 and Ser-136. Phosphorylation of either of these sites causes $\mathrm{Bad}$ to dissociate from Bcl- $\mathrm{X}_{\mathrm{L}}$ and to associate instead with cytoplasmic 14-3-3 proteins, adapter proteins that interact with a variety of signaling molecules in a phosphorylation-dependent manner (Muslin et al. 1996; Yaffe et al. 1997). Association of Bad with 14-3-3 proteins may protect Bad from dephosphorylation or sequester Bad away from its targets at the mitochondria. Cell lines expressing mutant alleles of Bad in which Ser112 and/or -136 are mutated undergo enhanced apoptosis, suggesting that phosphorylation of Bad disrupts its ability to bind to and inactivate $\mathrm{Bcl}-\mathrm{X}_{\mathrm{L}}$. Thus, phosphorylation of Bad inactivates its ability to cause cell death and promotes cell survival. Conversely, dephosphorylation of Bad results in targeting of Bad to mitochondrial membranes where Bad has been proposed to interact with and inactivate survival-promoting Bcl-2 family members and thereby induce cell death. Recently, calcineurin was shown to be a phosphatase capable of dephosphorylating Bad in vitro and in cells (Wang et al. 1999).

The Bad Ser-112 and Ser-136 phosphorylation sites are conserved in all Bad isoforms so far identified, suggesting that these sites play an important role in regulating Bad function (Fig. 3A). These sites also both lie within consensus sequences that correspond to the Akt phosphorylation site, and Akt was found to potently phosphorylate Bad in vitro (Datta et al. 1997; Del Peso et al. 1997). Although Ser-112 corresponds to a consensus site for phosphorylation by Akt, Akt preferentially phosphorylates Bad at Ser-136. Consistent with the direct regulation of Bad by Akt, both Bad and Akt coimmunoprecipitate when overexpressed and interact in GST-pulldown experiments (Datta et al. 1997; Blume-Jensen et al. 1998). In addition, indirect immunofluorescence microscopy reveals that Akt and Bad are colocalized within cells, providing further evidence for a direct Akt-Bad interaction (Blume-Jensen et al. 1998).

Akt activity was found to be both necessary and sufficient for Ser-136 phosphorylation in vivo (Fig 3B). Cotransfection of constitutively active Akt alleles together with Bad results in increased levels of Ser-136 phosphorylation (Datta et al. 1997; Del Peso et al. 1997; Blume-Jensen et al. 1998; Wang et al. 1999). In addition, transfection of 3T3 cells with active Akt alleles is sufficient to induce the phosphorylation of endogenous Bad

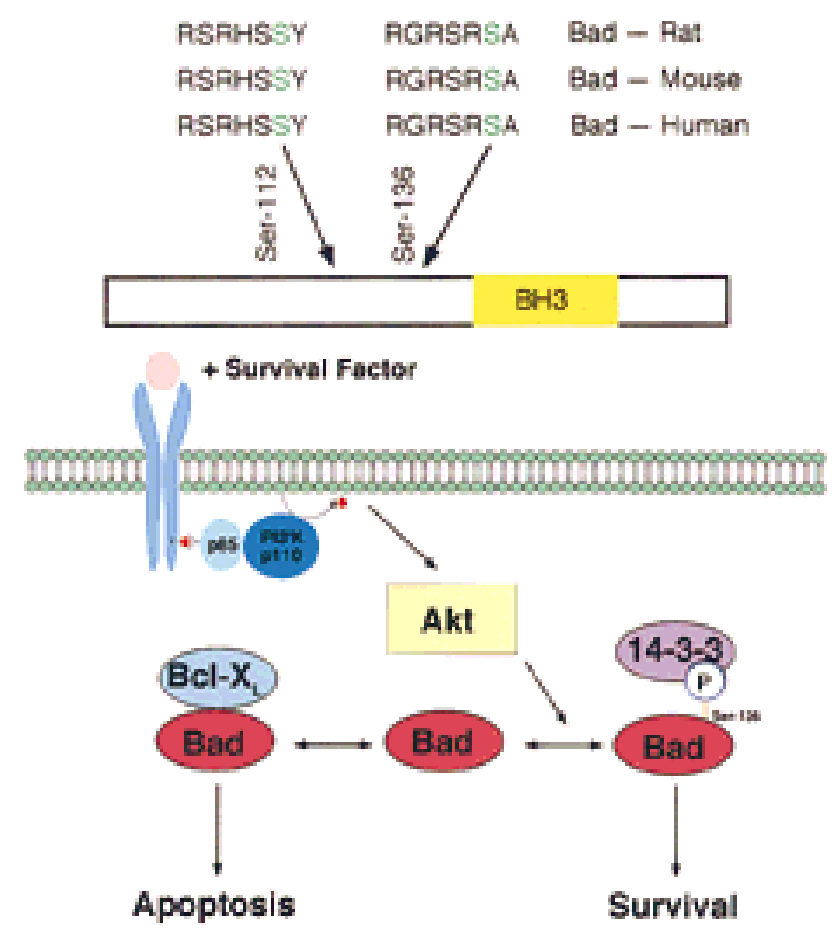

Figure 3. Bad is a Bcl-2 family member regulated by phosphorylation by Akt at Ser-136. (A) Domain structure and alignment of the phosphorylation sites within Bad. (B) Model of growth factor-mediated phosphorylation and inactivation of Bad. Survival factors activate Akt, which phosphorylates Bad on Ser-136, resulting in its inactivation and cell survival. In the absence of survival factors and Akt activity, Bad is dephosphorylated. Dephosphorylated Bad interacts with pro-survival Bcl-2 family members, such as Bcl- $\mathrm{X}_{\mathrm{L}}$ and inactivates them, causing cell death.

at Ser-136 (Datta et al. 1997), whereas transfection of cells with dominant-negative Akt alleles blocks phosphorylation of transfected Bad at Ser-136 (Datta et al. 1997; Del Peso et al. 1997; Wang et al. 1999a). Transfection of cells with constitutively active Akt alleles is also sufficient to induce the retention of endogenous Bad in the cytoplasm, consistent with the possibility that Akt blocks Bad-mediated death by preventing the interaction of Bad with its targets at the mitochondria (Wang et al. 1999a).

The biological importance of Akt phosphorylation of Bad at Ser-136 was demonstrated in single-cell apoptosis assays of transfected cells. The introduction of constitutively active Akt blocks Bad-induced apoptosis in multiple cell types (Datta et al. 1997; Blume-Jensen et al. 1998; Wang et al. 1999a). Constitutively active Akt alleles are unable to promote survival of cells cotransfected with Bad molecules in which Ser-136 has been converted to alanine. By contrast, mutation of Bad Ser-112 to alanine had no effect on the ability of Akt to suppress Badmediated apoptosis. These results suggest that Akt phosphorylates Bad at Ser-136 in vivo, which leads to the inactivation of Bad and thereby promotes cell survival.

The finding that Akt suppresses Bad-induced death by 
direct phosphorylation of Bad at Ser-136 is consistent with correlative evidence suggesting that the endogenous PI3K/Akt pathway culminates in the phosphorylation of endogenous Bad. A number of survival factors induce phosphorylation of both endogenous and transfected Bad (Zha et al. 1996; Datta et al. 1997; BlumeJensen et al. 1998; Davies et al. 1998; Myers et al. 1998; Scheid and Duronio 1998; Zundel and Giaccia 1998; Miho et al. 1999; Wang et al. 1999). In cells exposed to these factors, an increase in Akt activity correlates with an increase in Bad phosphorylation, and for each of these factors, it has been demonstrated that blockade of PI3K activity inhibits both Akt activity and Bad phosphorylation. Using transfected c-kit receptor mutants it has also been demonstrated that Bad phosphorylation depends on the presence of receptor phosphotyrosines that interact with PI3K, further suggesting that PI3K activation can lead to Bad phosphorylation (Blume-Jensen et al. 1998).

Indirect evidence also supports the hypothesis that endogenous Akt phosphorylates and inactivates the apoptotic activity of endogenous Bad. GF-independent activation of Akt is tightly correlated with endogenous Bad phosphorylation at Ser-136. For example, a number of PTEN-deficient tumor cell lines, due to the elevation of 3 '-phosphorylated phosphoinositides, have elevated Akt activity and a concomitant increase in Bad phosphorylation; the elevation in Akt activity and Bad phosphorylation is reverted in concert when wild-type PTEN is reintroduced into mutant PTEN cell lines (Davies et al. 1998; Myers et al. 1998). PTEN activity downregulates both Akt activity and Bad phosphorylation even in cell types in which decreases in Akt activity do not result in apoptosis (Davies et al. 1998; Myers et al. 1998). Similarly, PI3K-independent activation of Akt by calcium-dependent activation of CaMKK increases Bad phosphorylation; conversely, when calcium-induced Akt activity is blocked by transfection of cells with dominant-negative CaMKK alleles, calcium-induced Bad phosphorylation is also inhibited (Yano et al. 1998). In addition, stimuli that through as-yet uncharacterized mechanisms downregulate Akt activity, including ceramide, UV, IR, and sorbitol, each also inhibit Bad phosphorylation (Zundel and Giaccia 1998). It is interesting to note that the expression of Bad itself has been shown to be upregulated in response to apoptotic stimuli or during pathologic processes such as Alzheimer's disease (Kitamura et al. 1998; Tang et al. 1998; Mok et al. 1999)

Data from transgenic mice that overexpress Bad in their thymuses also suggest that Akt activity and Bad phosphorylation are functionally coregulated (Mok et al. 1999). As might be expected, the number of $\mathrm{T}$ cells in these transgenic mice is significantly reduced. Moreover, Bad-overexpressing $T$ cells that survive are acutely sensitive to PI3K inhibition. That these Bad-overexpressing $\mathrm{T}$ cells survive at all was rationalized by the finding that these cells have threefold elevated Akt activity. The Akt activity, which results in the phosphorylation and inactivation of the overexpressed Bad, possibly stems from the autocrine production of survival factors. Thus cells may naturally adapt to elevations in the level of Bad expression by activating Akt. This observation is consistent with the possibility that Bad is a target of endogenous Akt survival signals.

Bad likely represents a convergence point for a number of kinases that are capable of phosphorylating the RXRXXS consensus sequence. Several kinases, including PKA, $\mathrm{Ca}^{2+} / \mathrm{CaMKII}, \mathrm{Ca}^{2+} / \mathrm{CaMK}$ IV, and pp90 ${ }^{\mathrm{RSK}} \mathrm{S}$, phosphorylate Bad in vitro (Datta et al. 1997; Bonni et al. 1999|. Two of these kinases, PKA and the $\mathrm{pp} 90^{\mathrm{RSK}} \mathrm{s}$, suppress Bad function in vivo through phosphorylation of Ser-112 (Bonni et al. 1999; Harada et al. 1999; Shimamura et al. 1999). Transfection of cells with an active Raf that is targeted to the mitochondrial outer membrane also induces Bad phosphorylation and suppresses apoptosis, suggesting that a Raf-controlled kinase cascade may regulate Bad function independently of Akt (Wang et al. 1996). The site(s) of Raf-induced BAD phosphorylation are not yet known but appear to be distinct from Ser-136 and Ser-112. Consistent with the possibility that Akt is not required for Bad phosphorylation in all cells, GM-CSF treatment of cells results in both survival and Bad phosphorylation in the absence of PI3K and Akt activity (Scheid and Duronio 1998). Therefore, depending on the particular survival stimulus, the PI3K/Akt cascade may not be strictly required to inhibit Bad-dependent death. Rather, other kinase cascades may phosphorylate BAD at sites other than Ser-136 that then lead to the suppression the apoptotic function of BAD. Evidence that other signaling cascades lead to Bad inactivation is consistent with data demonstrating that different survival stimuli can synergize to support cell survival (Meyer-Franke et al. 1995).

Findings that demonstrate that survival factors and Akt act to block cytochrome $\mathrm{C}$ release from mitochondria may reflect an important role for Bad in Akt survival signaling (Juin et al. 1999; Kennedy et al. 1999). However, the existence of additional Akt targets is suggested by data demonstrating that there are tissues in which Akt promotes survival in which Bad appears not to be expressed (Yang et al. 1995; Kaipia et al. 1997; Kitada et al. 1998). These targets may include proteins (such as yet-unidentified Bad homologs) that regulate the mitochondrial release of cytochrome $\mathrm{C}$, or proteins that act at other stages of the apotpotic process.

\section{Caspase 9}

An interesting clue to the identity of additional Akt targets came from data demonstrating that Akt can block cell death even after mitochondrial cytochrome $\mathrm{C}$ release. For example, NGF is capable of blocking apoptosis induced by microinjection of cytochrome C into cultured sympathetic neurons in a manner that is independent of new gene expression (Deshmukh and Johnson 1998). The ability of growth factors to block cell death subsequent to increases in cytoplasmic cytochrome C may be attributed in part to the PI3K-Akt survival pathway. This idea is supported by the finding that caspases in lysates from cell lines that overexpress constitutively active Ras or Akt are not activated effectively by the 
addition of cytochrome $\mathrm{C}$ to the lysates (Cardone et al. 1998). Because the best-defined target for cytochrome C is the apoptosome, these results suggested that Akt may regulate apoptosome function. Indeed, immunoprecipitating overexpressed caspase 9 from ${ }^{32} \mathrm{P}$-labeled cells revealed that Akt phosphorylates caspase 9 at Ser-196 (Cardone et al. 1998). This phosphorylation event has functional consequences, as extracts from cell lines overexpressing Akt block cytochrome C-mediated caspase 9 activation in vitro (Cardone et al. 1998). In 293 cells Akt can suppress caspase 9-induced cell death in a manner that is partially dependent on the phopshorylation of Ser196.

These results suggest that Akt promotes survival through the inactivation of caspase 9 downstream of cytochrome $\mathrm{C}$ release. Importantly, Akt does not act as a generalized caspase inhibitor. Constitutively active Akt alleles are ineffective at either phosphorylating caspase 3 or 8 in vitro or blocking caspase 8 -induced death /Cardone et al. 1998; Rohn et al. 1998.). It is not clear how phosphorylation of caspase 9 results in its inactivation, although it appears to inactivate the intrinsic catalytic activity of the caspase 9. The phosphorylation of caspase 9 may represent a mechanism by which survival factors ensure cellular survival, even under conditions in which some quantity of cytochrome $\mathrm{C}$ has been released from mitochondria. In addition, Akt phosphorylation of caspase 9 demonstrates that survival factors likely regulate cytoplasmic apoptotic events both at the level of mitochondria and downstream of the mitochondria.

\section{Forkhead family members}

Many apoptotic stimuli not only activate the extant cell death machinery but also induce de novo gene expression. A variety of cell types require transcription for the induction of apoptosis, suggesting that a specific program of gene expression must be executed for apoptosis to occur. For example in neurons, apoptosis induced by survival factor withdrawal is suppressed when cells are treated with transcription or translation inhibitors (Galli et al. 1995; Miller and Johnson 1996). The genes involved may encode critical members of the apoptotic machinery; for instance, the gene encoding Bax is upregulated in response to apoptotic stimuli (Miyashita et al. 1994; Zhan et al. 1994; Miyashita and Reed 1995). The genes whose expression is upregulated by apoptotic stimuli may encode other proteins involved in processes such as release of cytochrome $c$ from the mitochondrial intermembrane space (Deshmukh and Johnson 1998). Finally, apoptotic stimuli promote the expression of genes encoding cytokines such as Fas ligand or tumor necrosis factor $\alpha$ (Sung et al. 1991; Rhoades et al. 1992; Dockrell et al. 1998; Faris et al. 1998; Li-Weber et al. 1998; LeNiculescu et al. 1999), that in turn propagate the apoptotic process through binding to their cognate receptors at the cell surface (Nagata 1997). However, for the most part the specific genes that are upregulated remain to be identified.

One mechanism by which Akt appears to regulate apoptosis is by modulating the expression of a defined subset of genes involved in death. This was suggested by the finding that within $30 \mathrm{~min}$ of their activation by growth factors, both Akt1 and Akt2 detach from the inner surface of the plasma membrane, where they are initially activated, and relocalize to the nucleus (Andjelkovic et al. 1997; Meier et al. 1997). In the nucleus, Akt isoforms have been hypothesized to phosphorylate and modulate the activity of transcription factors. Critical steps toward identifying a family of transcription factors whose function is regulated by Akt has come from two separate lines of investigation. Early studies revealed that members of the Forkhead family of transcription factors interact with an insulin-response sequence (IRS) (Unterman et al. 1994; O'Brien et al. 1995; Powell et al. 1995). The IRS has been identified in the promoter of several genes such as IGF-binding protein 1 (IGFBP1) (Suwanickul et al. 1993; Goswami et al. 1994), phosphoenolpyruvate kinase (PEPCK) (O'Brien et al. 1990), apolipoprotein CIII (Li et al. 1995), or glucose-6-phosphatase (Dickens et al. et al. 1998) and has been shown to mediate Akt-dependent transcriptional repression of these genes (Sutherland et al. 1995; Streeper et al. 1997; Cichy et al. 1998; Dickens et al. 1998; Liao et al. 1998). In a separate line of investigation, two groups studying diapause and longevity in $C$. elegans provided critical data indicating that DAF-16, a Forkhead family member, is a major target of the PI3K-Akt pathway. In the nematode, the PI3K-Akt signaling pathway is conserved and controls at least two biological responses: the exit from the dauer larvae stage and aging in the adult stage (Morris et al. 1996; Kimura et al. 1997; Paradis and Ruvkun 1998; Paradis et al. 1999). Genetic screens for suppressors of the PI3K mutants in the nematode led to the identification of a transcription factor of the Forkhead family called DAF-16 (Lin et al. 1997; Ogg et al. 1997). These genetic findings together with the recent discovery of Akt in C. elegans imply that PI3K-Akt pathway antagonizes DAF-16 function (Lin et al. 1997; Ogg et al. 1997; Paradis and Ruvkun 1998). Interestingly, all of the alleles identified in the suppressor screen were found in daf-16, suggesting that in the nematode $d a f-16$ is the major target for the PI3K-Akt pathway.

In mammalian cells, three members of the Forkhead family have been identified that are likely DAF-16 orthologs. These three isoforms (FKHR, FKHRL1/AF6q21, and AFX) were identified at the sites of chromosomal rearrangements in certain human tumors (Davis et al. 1995; Sublett et al. 1995; Borkhardt et al. 1997; Hillion et al. 1997; Anderson et al. 1998b). Each of the three mammalian DAF-16 homologs share a core domain of 100 amino acids, called the Forkhead domain, that mediates their interaction with DNA. The carboxy-terminal domain of AFX and the related Forkhead isoforms correspond to the transcriptional activation domains of these transcriptional regulators (Kops et al. 1999) (Fig. 4).

An analysis of DAF-16 in the nematode and all three human forkhead isoforms reveals three sequences that correspond to the Akt consensus phosphorylation site (Fig. 4; Table 3). The conservation of these putative Akt 


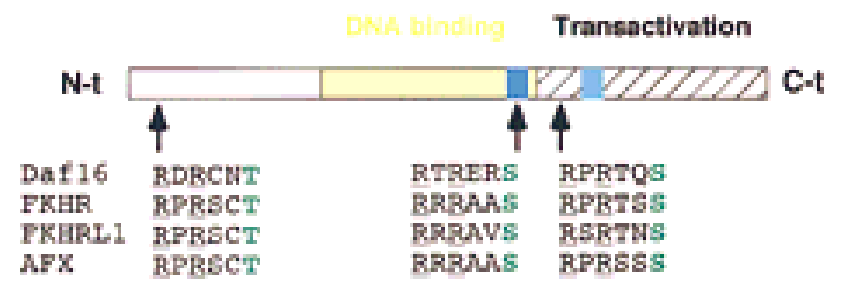

paseve nes

pulative Ne:

Figure 4. Domain structure and phosphorylation sites within Forkhead family transcription members.

phosphorylation sites throughout evolution suggested that they might be important functionally. Akt was recently shown to effectively phosphorylate the nematode DAF-16, human FKHRL1, FKHR, and AFX and mouse FKHR in vitro (Biggs et al. 1999; Brunet et al. 1999; Kops et al. 1999; Rena et al. 1999; Tang et al. 1999; S. Ogg and G. Ruvkun, pers. comm.). The major site of phosphorylation of these Forkhead isoforms in vitro appears to be the second site, which is located within the conserved DNA binding domain (Fig. 4) (Biggs et al. 1999; Brunet et al. 1999; Kops et al. 1999; Nakae et al. 1999; Rena et al. 1999). The other two phosphorylation sites also appear to be phosphorylated in vitro, although less efficiently than the second site. The expression of a constitutively active version of Akt within cells is sufficient to induce the phosphorylation of all three Forkhead isoforms at all three sites (Biggs et al. 1999; Brunet et al. 1999; Kops et al. 1999; Rena et al. 1999). The phosphorylation of transfected and endogenous Forkhead isoforms at each of the three sites is induced upon exposure of a variety of cell types to IGF-1. The induction of phosphorylation is blocked when the cells are pre-treated with the PI3K inhibitor LY294002, suggesting that PI3K activity is necessary for the phosphorylation of Forkhead isoforms.

Akt-mediated phosphorylation modulates the func-

Table 3. Transcription factors that contain the Akt consensus phosphorylation site

\begin{tabular}{|c|c|c|c|c|c|}
\hline Transcription factor & \multicolumn{3}{|c|}{ Akt potential phosphorylation sites } & Species & Role of the TF \\
\hline \multicolumn{6}{|l|}{ Forkhead family } \\
\hline FKHR & RPRSCTW & RRRAVSM & RSRTNSN & human & rhabdomyosarcoma \\
\hline FKHRL1 & $\overline{\mathrm{R}} \mathrm{PRSCTW}$ & $\bar{R} P \bar{R} A A S M$ & $\overline{\mathrm{R}} \mathrm{PRTSSN}$ & human & leukemia \\
\hline AFX & $\underline{\mathrm{R}} \mathrm{P} \underline{\mathrm{R}} \mathrm{SCTW}$ & $\underline{\bar{R}} R \bar{R} A A S M$ & $\underline{\bar{R}} \mathrm{P} \underline{\mathrm{R}} S S S N$ & human & \\
\hline DAF16a & RDRCNTW & RTRERSN & RPRTQSN & nematode & Dauer formation \\
\hline DAF16b & $\overline{\mathrm{R}} \mathrm{\overline {R }} \mathrm{CYTW}$ & RTRERSN & RPRTQSN & nematode & aging \\
\hline BF-1/ c-qin & & $\underline{R} R$ RTTS & & $\begin{array}{l}\text { human/mouse/rat } \\
\text { zebra fish/chicken }\end{array}$ & oncogenesis \\
\hline BF-2 & & $\underline{R R} \underline{R} G P S S$ & & human & \\
\hline \multicolumn{6}{|l|}{ Nuclear receptor family } \\
\hline \multicolumn{6}{|l|}{ POU family } \\
\hline Brn3 & & RKRKRTS & & human/mouse/zebra fish & \\
\hline POU6F1/Brn5 & & $\underline{\bar{R}} K \bar{R} R T S F$ & & human & terminal differentiation \\
\hline POU2 & & $\underline{\mathrm{R}} \mathrm{K} \mathrm{R} R T S L$ & & zebra fish & $\begin{array}{l}\text { early embryonic } \\
\text { development }\end{array}$ \\
\hline \multicolumn{6}{|l|}{ HLH family } \\
\hline TAL-1/SCL & & $\underline{\mathrm{R}}(\mathrm{H} / \mathrm{L}) \underline{\mathrm{R} V P T T}$ & & human/mouse & $\begin{array}{l}\text { erythroid differentiation } \\
\text { leukemia }\end{array}$ \\
\hline \multicolumn{6}{|l|}{ bHLH family } \\
\hline MATH1 & & RQRAPSS & & mouse & \\
\hline neurogenin2/MATH4B & & RSRAVSR & & mouse & neurogenesis \\
\hline neurogenin3/MATH5 & & RNRPKSE & & mouse & \\
\hline myogenin & & RRRATL & & rat/pig/quail & muscle differentiation \\
\hline HIF $\beta / A R N T$ & & $\underline{\mathrm{R}} \mathrm{M} C G(\mathrm{~S} / \mathrm{T}) \mathrm{S}$ & & human/mouse/rat & hypoxic response \\
\hline BMAL & & RSRWFSF & $\underline{\text { RIRGSSP }}$ & human/mouse/rat & \\
\hline \multicolumn{6}{|l|}{ Homeobox family } \\
\hline LIM3 & & RSRG(S/T)SK & & mouse/chicken & cell specification in the CNS \\
\hline NKX1.1/SAX-1 & & $\overline{\mathrm{R}}(\overline{\mathrm{A}} / \mathrm{R})$ RAESS & & mouse/chicken & cell specification in the CNS \\
\hline \multicolumn{6}{|l|}{ bZIP family } \\
\hline FosB & & $\underline{R R} \underline{R E L T D}$ & & human/mouse & oncogenesis \\
\hline GADD153/CHOP & & $\underline{\mathrm{R}} \mathrm{K} \overline{\mathrm{R}} \mathrm{KQSG}$ & & human/mouse & oncogenesis/growth arrest \\
\hline \multicolumn{6}{|l|}{ Zinc finger family } \\
\hline GATA1 & & RNRKASG & & human/mouse/rat & \\
\hline GATA2 & & $\underline{\bar{R}} N \underline{\bar{R}} K M S(N / S)$ & & human/mouse/chicken & erythroid development \\
\hline GATA3 & & $\underline{\underline{R}} N \underline{R} K M S S$ & & human/mouse/chicken & \\
\hline
\end{tabular}

These proteins were identified as described in the legend of Table 2. 
tion of Forkhead family members primarily through regulation of their subcellular localization (Biggs et al. 1999; Brunet et al. 1999). Under conditions during which Akt is activated, FKHR and FKHRL1 are phosphorylated and are retained in the cytoplasm. Under conditions during which Akt is inactive, these Forkhead family members are not phosphorylated and are relocalized to the nucleus (Biggs et al. 1999; Brunet et al. 1999). A mutant of FKHRL1 in which all three sites of Akt phosphorylation are converted to alanine is localized to the nucleus even in the presence of survival factors, indicating that the cytoplasmic retention of FKHRL1 is linked directly to its phosphorylation by Akt (Brunet et al. 1999). The finding that Akt promotes the cytoplasmic retention of the Forkhead transcription factors, and thereby sequesters them from their nuclear target genes, is consistent with the genetic evidence that Akt antagonizes the function of DAF-16 (Paradis and Ruvkun 1998) (Fig. 5A).

Whether Akt primarily phosphorylates Forkhead isoforms in the cytoplasm or in the nucleus is not yet clear. Depending on the subcellular compartment in which
Akt phosphorylates Forkhead isoforms, the phosphorylation of Forkhead transcription factors may either inhibit a nuclear localization signal (NLS)-dependent nuclear import or promote a nuclear export signal (NES)dependent nuclear export. The sequence of Forkhead family members contains both a potential NLS and NES (Fig. 4), consistent with both of these possibilities. An inhibitor of nuclear export, leptomycin B, prevents FKHR cytoplasmic relocalization upon growth factor treatment, suggesting that phosphorylation of Forkhead members by Akt may affect the recognition of the export signals by the exportin (Biggs et al. 1999). Since, like BAD, FKHRL1 has been shown to interact with 14-3-3 proteins (Brunet et al. 1999), 14-3-3 may serve as a general chaperone molecule for Akt targets, and may participate in the anchoring of the phosphorylated form of Forkhead transcription factors within the cytoplasm. Alternatively 14-3-3 binding may play an active role in the export of Forkhead transcription factors, as was shown for Cdc25 (Lopez-Girona et al. 1999).

Akt-mediated sequestration of Forkhead family mem-
Figure 5. Akt phosphorylation of Forkhead family members blocks apoptosis through regulation of cell death genes, including potentially FasL. $(A)$ In the presence of survival factors, activated Akt phosphorylates Forkhead family members, resulting in their sequestration in the cytoplasm. $(B)$ In the absence of survival factors and Akt activity, Forkhead family members translocate to the nucleus, where they initiate a program of gene expression. This program may include the FasL gene. FasL, acting in an autocrine or paracrine manner, activates the cell surface Fas protein, which in turn, activates a caspase cascade and causes cell death.

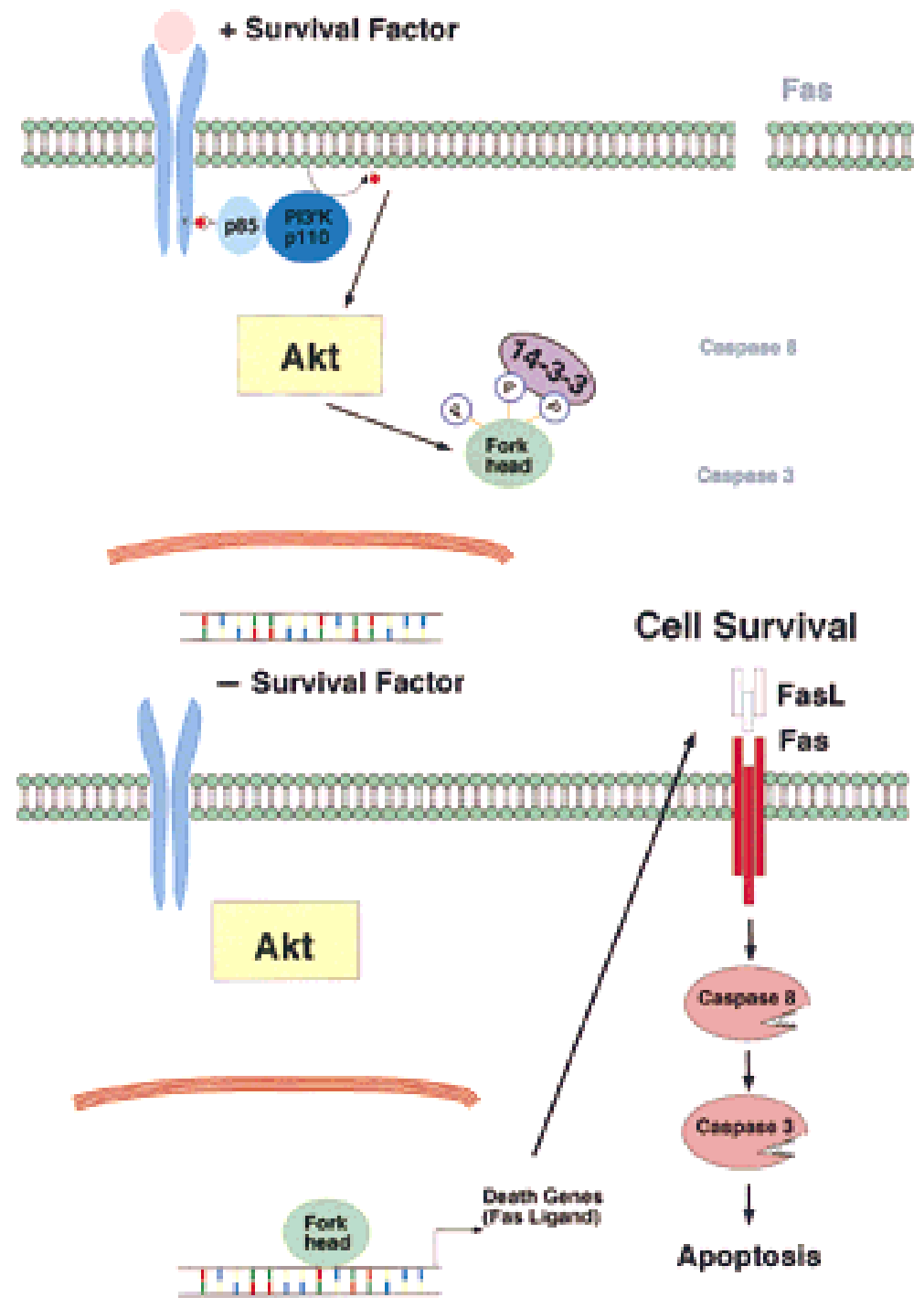


bers in the cytoplasm has functional consequences for Forkhead-dependent transcription (Biggs et al. 1999; Brunet et al. 1999; Guo et al. 1999; Kops et al. 1999; Tang et al. 1999|. In the absence of phosphorylation, Forkhead family members that are localized to the nucleus bind to specific DNA elements. Electrophoretic mobility shift assays indicate that AFX, FKHR, and FKHRL1 bind to the IRS within the IGFBP1 promoter (Brunet et al. 1999; Kops et al. 1999; Tang et al. 1999). In addition, FKHRL1 binds a cluster of Forkhead binding sites that is present in the promoter of the gene encoding Fas ligand (FasL) (Brunet et al. 1999).

Once bound to the promoters of target genes AFX, FKHR, and FKHRL1 all act as potent activators of transcription. The transactivating function of the Forkhead family members is repressed either by stimulation of cells with the survival factor IGF-1 or by the expression of constitutively active versions of PI3K or Akt. However, mutants of FKHRL1, FKHR, or AFX in which all three sites have been replaced by alanines are very potent activators of transcription and are insensitive to the repression by Akt, indicating that the repression of Forkhead-dependent transcription by Akt is due to the phosphorylation of Forkhead isoforms. This idea is supported by the finding that replacement of the phosphorylation sites, particularly the second site, by aspartic acid residues that mimic the presence of a phosphate group, is sufficient to disrupt the transactivation function of FKHR (Guo et al. 1999).

As Forkhead family members have been shown to be effective substrates of Akt, the relevance of this family to transcription-dependent apoptosis is of significant interest. Evidence that Forkhead family members can regulate apoptosis stems from the observation that the nonphosphorylatable mutants of FKHR or FKHRL1, which are potent transcriptional activator in the nucleus, trigger apoptosis in multiple cell types (Brunet et al. 1999; Tang et al. 1999). The apoptotic effect of the nonphosphorylatable mutant of FKHR is linked to its transcriptional activity, since a mutation in the DNA-binding domain which abolishes FKHR transcriptional activity also impairs the ability of FKHR to induce cell death (Tang et al. 1999). One death gene that is a potential target for Forkhead family members is the gene encoding the cytokine FasL. FasL gene is potently upregulated in neurons upon survival factor withdrawal (Le-Niculescu et al. 1999). Moreover, blocking FasL signaling reduces the apoptosis triggered by survival factor withdrawal in cerebellar granule neurons (Le-Niculescu et al. 1999). These results suggested an important role for FasL gene induction in survival factor withdrawal-induced apoptosis. The finding that FKHRL1 binds to sites present in the promoter of the FasL gene, and induces expression of a reporter gene driven by the FasL promoter (Brunet et al. 1999) has led to the hypothesis that in the absence of survival factors, when Akt is inactive, Forkhead family members may induce endogenous FasL gene transcription. FasL then binds to its cell surface receptor Fas in an autocrine or paracrine fashion, and triggers a cascade of events leading to apoptosis. Consistent with this idea, the induction of apoptosis that is triggered by the FKHRL1 phosphorylation site mutant can be reverted when FKHRL1 mutant expressing cells are treated with a soluble form of Fas that acts as a decoy receptor for the newly-synthesized FasL (Brunet et al. 1999). In addition, FKHRL1-induced apoptosis is also reverted when FKHRL1 phosphorylation site mutant is expressed in Jurkat cells that are genetically deficient for crucial components of the FasL signaling such as Fas or the adapter protein FADD. It remains to be demonstrated whether the endogenous FasL gene is controlled by Forkhead family members. However these findings suggest that one way Akt promotes survival is by phosphorylating and sequestrating Forkhead transcription factors in the cytoplasm, thereby preventing them from inducing the transcription of critical death genes, (Fig. 5A,B).

In addition to members of the Forkhead family, it is likely that a variety of other transcription factors will be found to be regulated by Akt. The transcriptional activator CREB was recently shown to be phosphorylated by Akt both in vitro and within cells at Ser-133, although Ser-133 does not conform to a canonical Akt phosphorylation site (Du and Montminy 1998). The phosphorylation of Ser-133 increases the binding of CREB to CBP and enhances CREB-mediated transcription (Du and Montminy 1998). In PC12 cells stimulated by IGF-1, blockade of PI3K activity leads to a decrease in CREB phosphorylation at Ser-133 and partially inhibits CREB transcriptional activation (Pugazhenthi et al. 1999). The relevance of the phosphorylation of CREB by Akt to apoptosis is also still unclear, although there is evidence that CREB regulates the expression genes critical for survival such as the gene encoding the cytokine BDNF (Shieh et al. 1998; Tao et al. 1998).

Finally, as shown in Table 3, a database search for proteins containing putative Akt phosphorylation sites has revealed that many transcription factors contain potential Akt phosphorylation within their sequence and could be Akt substrates. Notably, several of these transcriptional regulators have been implicated in oncogenesis. These Akt substrates may therefore regulate the balance between apoptosis and survival, a process that is altered in tumor cells. Clearly, identification of the array of Akt-regulated genes that are involved in cell survival and apoptosis, represents an important future step in understanding the mechanism by which Akt promotes survival and suppresses cell death.

\section{IKK: a link to $N F-\kappa B$}

The finding that Akt regulates apoptosis via the direct phosphorylation and inactivation of Bad, caspase 9, and the Forkhead transcription factors is consistent with the observation that growth factors in several systems can promote survival through post-translational mechanisms (Datta and Greenberg 1998). However, in vivo, growth factors likely also prevent cell death through upregulating genes capable of promoting survival. In addition, the ability of apoptotic stimuli (such as TNF $\alpha$ ) to induce cell death is limited by negative feedback mecha- 
nisms that involve the regulated expression of survival genes (Sonenshein 1997; Foo and Nolan 1999). Recent evidence has implicated Akt as a signaling intermediate upstream of survival gene expression that is dependent on the transcription factor NF- $\mathrm{B}$.

$\mathrm{NF}-\kappa \mathrm{B}$ is a ubiquitous, heterodimeric transcription factor that is sequestered in the cytoplasm by proteins of the IкB family (for review, see May and Ghosh 1997; Mercurio and Manning 1999). Phosphorylation of IкB targets it for ubiquitination and proteasome-mediated degradation. Degradation of ІкB frees NF-кB, allowing its nuclear translocation and subsequent activation of its target genes. The kinase cascades that regulate IкB have been recently characterized. I $\mathrm{B}$ is regulated by a protein complex that includes two kinases, IKK $\alpha$ and IKK $\beta$, both of which are capable of phosphorylating ІкB. Stimuli that activate NF- $\mathrm{kB}$ do so through the regulation of distinct upstream kinases that, in turn, phosphorylate and activate either or both of the IKKs.

Akt has been shown to enhance the degradation of the I $\mathrm{B}$ Bs and to cooperate with other factors to induce

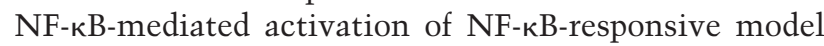
promoters (Kane et al. 1999). Akt has also been shown to be both necessary and sufficient for the ability of both PDGF and TNF to induce NF- $\mathrm{KB}$ transcriptional activity (Khwaja 1999; Ozes et al. 1999; Romashkova and Makarov et al. 1999). The ability of Akt to regulate NF-kB activity may be through direct interaction with the IKKs, as Akt can associate with the IKK complex in vivo. In addition, Akt has been shown to phosphorylate and activate IKK $\alpha$ at a critical regulatory site, Thr-23 (Ozes et al. 1999). Although the molecular details of how Akt regulates the IKK complex remain to be characterized, and appear to be in part cell-type specific, these data implicate Akt as part of a survival signaling pathway to NF-кB. The genes induced by NF-кB to promote survival are also still being identified, but include the pro-survival Bcl-2 family member Bfl-1/A1 and the caspase inhibitors c-IAP1 and c-IAP2 (Chu et al. 1997; You et al. 1997; Zong et al. 1999). Thus Akt may promote survival through regulation of the Bcl-2 family and the caspases both through direct phosphorylation, and through the induction of genes that regulate Bcl-2 family and caspase function.

\section{GSK-3: An Akt-dependent link between metabolism and survival?}

Before the identification of Akt as a mediator of cell survival, Akt was studied as a possible intermediary in the regulation of cellular metabolism by growth factors such as insulin and IGF-1. Akt was found to phosphorylate and inactivate glycogen synthase kinase-3 (GSK-3), which in turn regulates a number of substrates involved in cellular metabolism, including glycogen synthase (Cross et al. 1995; Hajduch et al. 1998; Pap and Cooper 1998; Shaw et al. 1997; Ueki et al. 1998; van Weeren et al. 1998). Recently, GSK-3 has been implicated as a mediator of the PI3K survival signal in Rat-1 and PC12 cells (Pap and Cooper 1998). Transfection of these cells with constitutively active GSK-3 induces apoptosis even in the presence of GFs; conversely, transfection of cells with kinase-inactive GSK-3 alleles blocks apoptosis.

The mechanism by which GSK-3 regulates cell survival is not known. One possibility is that Akt inactivation of GSK-3 inhibits the ability of GSK-3 to signal as part of the wingless pathway. Disruption of a number of components of this pathway have been implicated in disregulation of apoptosis (Zhang et al. 1998). However, it is not yet clear if the population of GSK-3 molecules regulated by Akt is the same as that involved in wingless signaling. It is also possible that Akt and GSK-3 promote survival indirectly by affecting cellular metabolism. Akt has been found, in part through its control of GSK-3, to regulate a number of processes involved in metabolism. These include effects on the activity of glycogen synthase, the translocation of the glucose transporter (GLUT) 4 to the plasma membrane, the induction of GLUT 1 synthesis and the activation of 6-phopshofructo-2-kinase (Kohn et al. 1996b, 1998; Deprez et al. 1997; Tanti et al. 1997; Hajduch et al. 1998; Summers et al. 1998; Wang et al. 1999). Although many of these processes are cell-type specific, Akt may generally regulate aspects of metabolic homeostasis. Consistent with this view is evidence that the major roles for Akt1 and Akt2 in the nematode are in the regulation of metabolism (Paradis and Ruvkun 1998). Recent data from Thompson and colleagues suggests that $\mathrm{Bcl}-\mathrm{X}_{\mathrm{L}}$ may promote survival by stabilizing the levels of intracellular ATP, perhaps through regulation of mitochondrial proteins such as the adenine nucleotide transporter (Vander Heiden et al. 1999). An interesting hypothesis that remains to be tested is that Akt, like Bcl- $\mathrm{X}_{\mathrm{L}}$, promotes survival by stabilizing intracellular ATP levels. It is possible that GSK-3 partially mediates Akt's effects on metabolism and thereby promotes cell survival.

\section{Act 3-finale: can the known substrates explain the Akt survival phenotype? Or, are there additional substrates waiting in the wings?}

With the identification of at least four Akt substratesBad, caspase 9, the Forkhead transcription factors, and IKK-that are central to the regulation of apoptosis, it is now possible to consider more comprehensive models that might explain how Akt promotes survival. In one such model Akt phosphorylates and inactivates multiple components of the apoptotic machinery, each of which may function in a cell- and stimulus-specific manner and is present in limited quantities. In addition, although each of these substrates when dephosphorylated is sufficient to induce apoptosis in the cell types in which it is expressed, none of these substrates is required for the induction of cell death under all circumstances. In addition to inactivating apoptosis-regulating proteins, Akt may induce the expression of survival genes. Therefore Akt may propagate survival signals through the phosphorylation and coordinate regulation of a variety of apoptotic regulators (Fig. 6).

While it remains to be determined if this model of Akt-mediated survival is valid, the identification of Bad, 


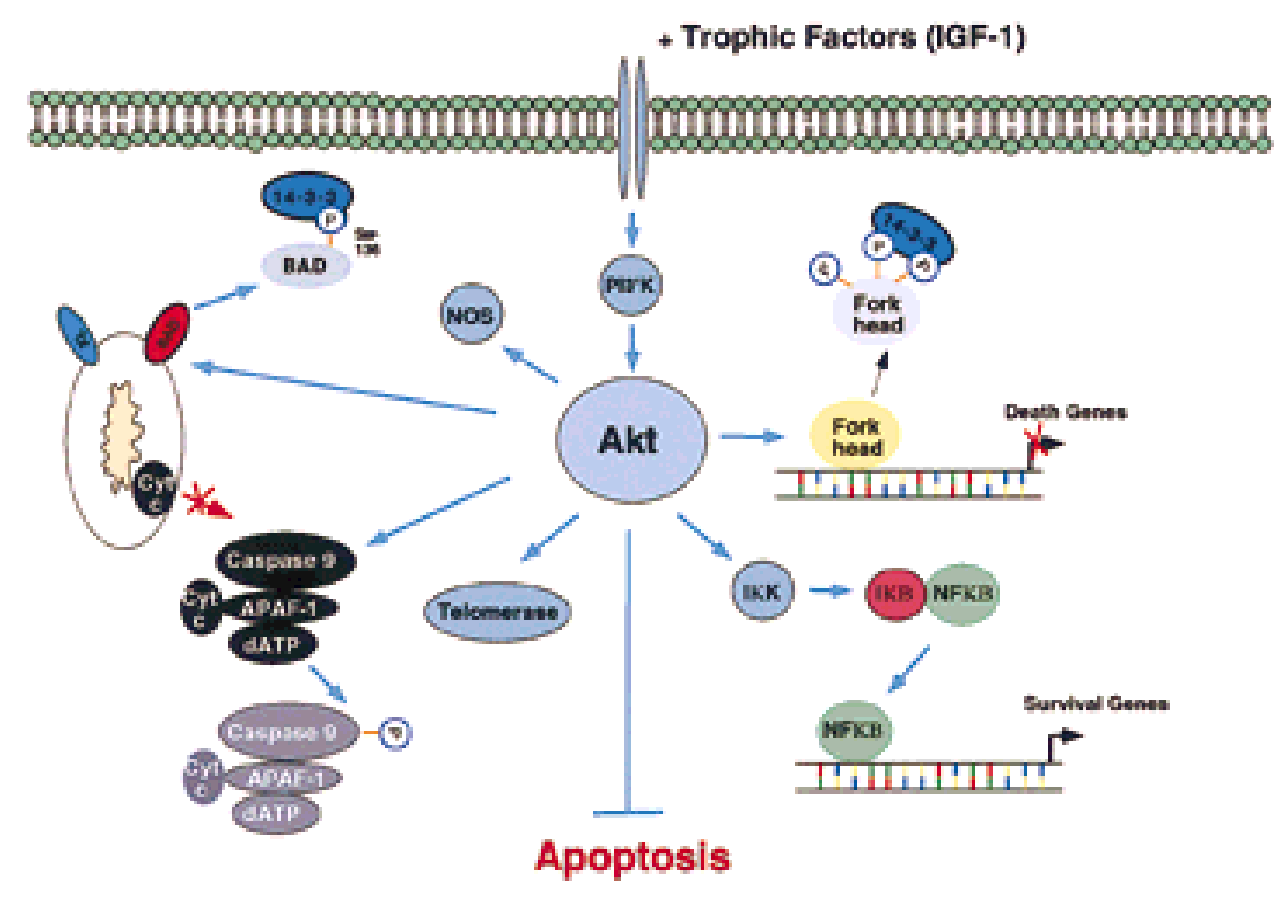

Figure 6. Akt regulates survival through the phosphorylation of multiple substrates involved in the regulation of apoptosis. Akt has thus far been shown to block apoptosis through regulation of the transcriptional activity of both Forkhead family members and NF- $\mathrm{B}$, and through phosphorylation and inactivation of the Bcl-2 homolog Bad and caspase-9. In addition, other targets for Akt, including telomerase and NOS, may play important roles in cellular survival.

caspase 9, the Forkhead proteins, and NF-кB as targets of the Akt survival signal has provided tantalizing clues as to the mechanism of the Akt-mediated survival effect. A number of additional substrates for Akt have been identified, including eNOS (Dimmeler et al. 1999; Fulton et al. 1999), phosphofructokinase-2 (Deprez et al. 1997), phosphodiesterase 3B (Wijkander et al. 1998) and the reverse transcriptase subunit of telomerase (Kang et al. 1999). Although none of these proteins has yet been directly implicated in GF-mediated cell survival, it is possible that these and/or as-yet-unidentified Akt substrates play a role in mediating the effects of Akt on survival. The possible existence of additional Akt targets has been suggested by the observation that Akt can block Fas-mediated apoptosis, a finding that is not satisfactorily explained by the phosphorylation of known substrates (Hausler et al. 1998; Rohn et al. 1998; Gibson et al. 1999). In addition, data demonstrating that Akt can block cytochrome $\mathrm{C}$ exit from mitochondria, both in cells that express Bad and in cells that do not express detectable levels of $\mathrm{Bad}$, implies that Akt may regulate a protein that acts in a manner similar to Bad to control mitochondrial-dependent cell death (Juin et al. 1999; Kennedy et al. 1999). Consistent with this possibility, Akt has recently been shown to block death induced by the Bcl-2 family members Bax and Bid (Kennedy et al. 1999 ).

It is important to note that there are likely proteins related to Akt that are capable of promoting cellular survival downstream of PI3K and the PDKs. These parallel signaling pathways may redundantly regulate many of the targets so far identified as important for Akt-mediated survival. Thus the elucidation of the mechanisms by which Akt promotes survival may serve as a paradigm, rather than a complete picture, for the action of survival factors.

Although there are many remaining questions regarding the mechanisms by which PI3K and Akt promote survival, the identification of the PI3K/Akt cascade as a critical component of survival signaling represents a major step forward in linking extracellular survival factors to the intracellular apoptotic machinery. The central role that this pathway plays in trophic factor-mediated survival suggests that it will remain the focus of intense research activity in the coming years.

\section{Acknowledgments}

We apologize for the failure to cite many of the important and relevant papers in this field due to space limitations. We thank K.C. Arden, B.M.T. Burgering, Y. Gotoh, N. Hay, G. Ruvkun, T. Unterman, and the anonymous reviewer for useful comments on the manuscript and for communicating results before publication. We also thank, Alex Katsov and members of the Greenberg lab for assistance with the manuscript.

\section{References}

Ahmed, N.N., H.L. Grimes, A. Bellacosa, T.O. Chan, and P.N. Tsichlis. 1997. Transduction of interleukin-2 antiapoptotic and proliferative signals via Akt protein kinase. Proc. Natl. Acad. Sci. 94: 3627-3632. 
Alberti, S. 1998. A phosphoinositide-binding sequence is shared by $\mathrm{PH}$ domain target molecules-a model for the binding of PH domains to proteins. Proteins 31: 1-9.

Alessi, D.R., M. Andjelkovic, B. Caudwell, P. Cron, N. Morrice, P. Cohen, and B.A. Hemmings. 1996a. Mechanism of activation of protien kinase B by insulin and IGF-1. EMBO $J$. 15: 6541-6551.

Alessi, D.R., F.B. Caudwell, M. Andjelkovic, B.A. Hemmings, and P. Cohen. 1996b. Molecular basis for the substrate specificity of protein kinase $\mathrm{B}$; comparison with MAPKAP kinase-1 and p70 S6 kinase. FEBS Lett. 399: 333-338.

Alessi, D.R., M. Deak, A. Casamayor, F.B. Caudwell, N. Morrice, D.G. Norman, P. Gaffney, C.B. Reese, C.N. MacDougall, D. Harbison et al. 1997a. 3-phosphoinositide-dependent protein kinase-1 (PDK-1): Structural and functional homology with the Drosophila DSTPK61 kinase. Curr. Biol. 7: 776-789

Alessi, D.R., S.R. James, C.P. Downes, A.B. Holmes, P.R.J. Gaffney, C.B. Reese, and P. Cohen. 1997b. Characterization of a 3-phosphoinositide-dependent protein kinase which phopshorylates and activates protein kinase B $\alpha$. Curr. Biol. 7: 261-269.

Alessi, D.R., M.T. Kozlowski, Q-P. Weng, N. Morrice, and J. Avruch. 1997c. 3-phosphoinositide-dependent protein kinase 1 (PDK1) phosphorylates and activates the p70 S6 kinase in vivo and in vitro. Curr. Biol. 8: 69-81.

Altomare, D.A., K. Guo, J.Q. Cheng, G. Sonoda, K. Walsh, and J.R. Testa. 1995. Cloning, chromosomal localization and expression analysis of the mouse Akt2 oncogene. Oncogene 11: $1055-1060$.

Altomare, D.A., G.E. Lyons, Y. Mitsuuchi, J.Q. Cheng, and J.R. Testa. 1998. Akt2 mRNA is highly expressed in embryonic brown fat and the AKT2 kinase is activated by insulin. Oncogene 16: 2407-2411.

Aman, M.J., T.D. Lamkin, H. Okada, T. Kurosaki, and K.S. Ravichandran. 1998. The inositol phosphatase SHIP inhibits Akt/PKB activation in B cells. J. Biol. Chem. 273: 3392233928.

Anderson, C.N.G. and A.M. Tolkovsky. 1999. A role for MAPK/ ERK in sympathetic neuron survival: Protection against a p53-dependent, JNK-independent induction of apoptosis by cytosine arabinoside. J. Neurosci. 19: 664-673.

Anderson, K.E., J. Coadwell, L.R. Stephens, and P.T. Hawkins. 1998a. Translocation of PDK-1 to the plasma membrane is important in allowing PDK-1 to activate protein kinase B. Curr. Biol. 8: 684-691.

Anderson, M.J., C.S. Viars, S. Czekay, W.K. Cavenee, and K.C. Arden. 1998b. Cloning and characterization of three human forkhead genes that comprise an FKHR-like gene subfamily. Genomics 47: 187-199.

Anjelkovic, M., T. Jakubowicz, P. Cron, X.-F. Ming, J.-W. Han, and B.A. Hemmings. 1996. Activation and phosphorylation of a pleckstrin homology domain containing protein kinase (RAC-PK/PKB) promoted by serum and protein phosphatase inhibitors. Proc. Natl. Acad. Sci. 93: 5699-5704.

Andjelkovic, M., D.R. Alessi, R. Meier, A. Fernandez, N.J.C. Lamb, M. Frech, P. Cron, P. Cohen, M. Lucocq, and B.A. Hemmings. 1997. Role of translocation in the activation and function of protein kinase B. J. Biol. Chem. 272: 3151531524.

Andjelkovic, M., H.S. Sudan, R. Meier, M. Frech, D.R. Alessi, and B.A. Hemmings. 1998. Nerve growth factor promotes activation of the alpha, beta and gamma isoforms of protein kinase B in PC12 pheochromocytoma cells. Eur. J. Biochem. 251: 195-200.

Aoki, M., O. Batista, A. Bellacosa, P. Tsichlis, and P.K. Vogt.
1998. The akt kinase: Molecular determinants of oncogenicity. Proc. Natl. Acad. Sci. 95: 14950-14955.

Balendran, A., A. Casamayor, M. Deak, A. Paterson, P. Gaffney, R. Currie, C.P. Downes, and D.R. Alessi. 1999. PDK1 acquires PDK2 activity in the presence of a synthetic peptide derived from the carboxyl terminus of PRK2. Curr. Biol. 9: 393-404.

Basu, S. and R. Kolesnick. 1998. Stress signals for apoptosis: Ceramide and c-Jun kinase. Oncogene 17: 3277-3285.

Basu, S., S. Bayoumy, Y. Zhang, J. Lozano, and R. Kolesnick. 1998. BAD enables ceramide to signal apoptosis via Ras and Raf-1. J. Biol. Chem. 273: 30419-30426.

Bellacosa, A., J.R. Testa, S.P. Staal, and P.N. Tsichlis. 1991. A retroviral oncogene, akt, encoding a serine threonine kinase containing an SH2-like region. Science 254: 274-277.

Bellacosa, A., T.F. Franke, M.E. Gonzalez-Portal, K. Datta, T. Taguichi, J. Gardner, J.Q. Cheng, J.R. Testa, and P.N. Tsichlis. 1993. Structure, expression and chromosomal mapping of c-akt: Relationship to $v$-akt and its implications. Oncogene 8: 745-754.

Bellacosa, A., D. de Feo, A.K. Godwin, D.W. Bell, J.Q. Cheng, D.A. Altomare, M. Wan, L. Dubeau, G. Scambia, V. Masciullo et al. 1995. Molecular alterations of the Akt2 oncogene in ovarian and breast carcinomas. Int. J. Cancer 64: 280-285.

Bellacosa, A., T.O. Chan, N.N. Ahmed, K. Datta, S. Malstrom, D. Stokoe, F. McCormick, J.Feng, and P. Tsichlis. 1998. Akt activation by growth factors is a multiple-step process: The role of the PH domain. Oncogene 17: 313-325.

Beraud, C., W.J. Henzel, and P.A. Baeuerle. 1999. Involvement of regulatory and catalytic subunits of phosphoinositide 3kinase in NF-кB activation. Proc. Natl. Acad. Sci. 96: 429434.

Bergmann, A., J. Agapite, K. McCall, and H. Steller. 1998. The Drosophila gene hid is a direct molecular target of ras-dependent survival signals. Cell 95: 331-341.

Berra, E., M.T. Diaz-Meco, and J. Moscat. 1998. The activation of p38 and apoptosis by the inhibition of erk is antagonized by the phosphoinositide 3-kinase/akt pathway. J. Biol. Chem. 273: 10792-10797.

Biggs, W.H., III, J. Meisenhelder, T. Hunter, W.K. Cavenee, and K.C. Arden. 1999. Protein kinase B/Akt-mediated phosphorylation promotes nuclear exclusion of the winged helix transctiption factor FKHR1. Proc. Nat1. Acad. Sci. 96: 74217426.

Blair, L.A.C., K.K. Bence-Hanulec, S. Metha, T. Franke, D. Kaplan, and J. Marshall. 1999. Akt-dependent potentiation of $\mathrm{L}$ channels by insulin-like growth factor- 1 is required by neuronal survival. J. Neurosci. 19: 1940-1951.

Blume-Jensen, P., R. Janknecht, and T. Hunter. 1998. The kit receptor promotes cell survival via activation of PI 3-kinase and subsequent Akt-mediated phosphorylation of Bad on Ser136. Curr. Biol. 8: 779-782.

Bonni, A., A. Brunet, A.E. West, S.R. Datta, and M.E. Greenberg. 1999. The ras-MAPK signaling pathway promotes cell survival via a dual transcription-dependent and transcriptionindependent mechanism. Science (in press).

Borasio, G.D., J. John, A. Wittinghofer, Y.-A. Barde, M. Sendtner, and R. Heumann. 1989. ras p21 protein promotes survival and fiber outgrowth of cultures embryonic neurons. Neuron 2: 1087-1096.

Borasio, G.D., A. Markus, A. Wittinghofer, Y.-A. Barde, and R. Heumann. 1993. Involvement of ras p21 in neurotrophininduced response of sensory, but not sympathetic neurons. $J$. Cell Biol. 121: 665-672.

Borkhardt, A., R. Repp, O.A. Haas, T. Leis, J. Harbott, J. Kreuder, J. Hammermann, T. Henn, and F. Lampert. 1997. Cloning 
and characterization of AFX, the gene that fuses to MLL in acute leukemias with a $\mathrm{t}(\mathrm{X} ; 11)(\mathrm{q} 13 ; \mathrm{q} 23)$. Oncogene 14: 195202.

Brennan, P., J.W. Babbage, B.M.T. Burgering, B. Groner, K. Reif, and D.A. Cantrell. 1997. Phosphatidylinositol 3-kinase couples the interleukin-2 receptor to the cell cycle regulator E2F. Immunity 7: 679-689.

Brodbeck, D., P. Cron, and B.A. Hemmings. 1999. A human protein kinase $\mathrm{B} \gamma$ with regulatory phosphorylation sites in the acitvation loop and in the C-terminal hydrophobic domain. J. Biol. Chem. 274: 9133-9136.

Brunet, A., A. Bonni, M.J. Zigmond, M.Z. Lin, P. Juo, L.S. Hu, M.J. Anderson, K.C. Arden, J. Blenis, and M.E. Greenberg. 1999. Akt promotes cell survival by phosphorylating and inhibiting a Forkhead transcription factor. Cell 96: 857-868.

Burgering, B.M. and P.J. Coffer. 1995. Protein kinase B (c-Akt) in phosphatidylinosotol-3-OH kinase signal transduction. $\mathrm{Na}$ ture 376: 599-602.

Cantley, L.C. and B.G. Neel. 1999. New insights into tumor suppression: PTEN suppresses tumor formation by restraining the phosphoinositide 3-kinase/AKT pathway. Proc. Natl. Acad. Sci. 96: 4240-4245.

Cardone, M.H., N. Roy, H.R. Stennicke, G.S. Salvasen, T.F. Franke, E. Stanbridge, S. Frisch, and J.C. Reed. 1998. Regulation of cell death protease caspase-9 by phosphorylation. Science 282: 1318-1321.

Chang, H.W., J. Li, D. Kretzschmar, and P.K. Vogt. 1995. Avian cellular homolog of the qin oncogene. Proc. Natl. Acad. Sci. 92: 447-451.

Chang, H.W., M. Aoki, D. Fruman, K.R. Auger, A. Bellacosa, P.N. Tsichlis, L.C. Cantley, T.M. Roberts, and P.K. Vogt. 1997. Transformation of chicken cells by the gene encoding the catalytic subunit of PI 3-kinase. Science 276: 1848-1850.

Chen, R.-H., Y.-H. Su, R.L.C. Chuang, and T.-Y. Chang. 1998. Suppression of transforming growth factor beta-induced apoptosis through a phosphatidylinositol 3-kinase/Akt-dependent pathway. Oncogene 17: 1959-1968.

Cheng, J.Q., B. Ruggeri, W.M. Klein, G. Sonoda, D.A. Altomare, D.K. Watson, and J.R. Testa. 1996. Amplification of AKT2 in human pancreatic cancer cells and inhibition of AKT2 expression and tunorigeneicity by antisense RNA. Proc. Nat1. Acad. Sci. 93: 3636-3641.

Cichy, S.B., S. Uddin, A. Danilkovich, S. Guo, A. Klippel, and T.G. Unterman. 1998. Protein kinase B/Akt mediates effects of insulin on hepatic insulin- like growth factor-binding protein-1 gene expression through a conserved insulin response sequence. J. Biol. Chem. 273: 6482-6487.

Clark, E.A. and J.S. Brugge. 1995. Integrins and signal transduction pathways: The road taken. Science 268: 233-239.

Coffer, P.J. and J.R. Woodgett. 1991. Molecular cloning and characterization of a novel putative protein-serine kinase related to the cAMP-dependent and protein kinase $\mathrm{C}$ families. Eur. J. Biochem. 201: 475-481.

Coffer, P.J., R.C. Schweitzer, G.R.. Dubois, T. Maikoe, J.-W.J. Lammers, and L. Koenderman. 1998. Analysis of signal transduction pathways in human eosinophils activated by chemoattractants and the T-helper 2-derived cytokines interleukin-4 and interleukin-5. Blood 91: 2547-2557.

Collin, R. 1906. Recherches cytologiques sur le developement de la cellule nerveuse. Nevraxe 8: 181-307.

Cross, D.A., D.R. Alessi, P. Cohen, M. Andjelkovich, and B.A. Hemmings. 1995. Inhibition of glycogen synthase kinase-3 by insulin mediated by protein kinase B. Nature 378: 785789 .

Crowder, R.J. and R.S. Freeman. 1998. Phosphatidylinositol 3-kinase and akt protein kinase are necessary and sufficient for the survival of nerve growth factor-dependent sympathetic neurons. J. Neurosci. 18: 2933-2943.

Cryns, V. and J. Yuan. 1998. Proteases to die for. Genes \& Dev. 12: $1551-1570$.

Currie, R.A., K.S. Walker, A. Gray, M. Deak, A. Casamayor, C.P. Downes, P. Cohen, D.R. Alessi, and J. Lucocq. 1999 Role of phosphatidylinositol 3,4,5-trisphosphate in regulating the activity and localization for 3-phosphoinositide-dependent protein kinase-1. Biochem. J. 337: 575-583.

Datta, K., T.F. Franke, T.O. Chan, A. Makris, S.-I. Yang, D.R. Kaplan, D.K. Morrison, E.A. Golemis, and P.N. Tsichlis. 1995. AH/PH domain-mediated interaction between Akt molecules and its potential role in Akt regulation. Mol. Cell. Biol. 15: 2304-2310.

Datta, K., A. Bellacosa, T.O. Chan, and P.N. Tsichlis. 1996. Akt is a direct target of the phosphatidylinositol 3-kinase. J. Biol. Chem. 271: 30835-30839.

Datta, S.R. and M.E. Greenberg. 1998. Molecular mechanisms of neuronal survival and apoptosis. In Hormones and Signaling (ed. B. O'Malley), pp. 257-305. Academic Press, San Diego, CA.

Datta, S.R., H. Dudek, X. Tao, S. Masters, H. Fu, Y. Gotoh, and M.E. Greenberg. 1997. Akt phosphorylation of BAD couples survival signals to the cell-intrinsic death machinery. Cell 91: 231-241.

Davies, M.A., Y. Lu, X. Fang, P. Tang, R. LaPushin, D. Koul, R. Bookstrin, D. Stokoe, W.K.A. Yung, G.B. Mills et al. 1998. Adenoviral transgene expression of MMAC/PTEN in human glioma cells inhibits akt activation and induces anoikis. Cancer Res. 58: 5285-5290.

Davis, R.J., J.L. Bennicelli, R.A. Macina, L.M. Nycum, J.A. Biegel, and F.G. Barr. 1995. Structural characterization of the FKHR gene and its rearrangement in alveolar rhabdomyosarcoma. Hum. Mol. Genet. 4: 2355-2362.

Del Peso, L., M. Gonzalez-Garcia, C. Page, R. Herrera, and G. Nuñez. 1997. Interleukin-3-induced phosphorylation of BAD through the protein kinase Akt. Science 278: 687-689.

Delcommenne, M., C. Tan, V. Gray, L. Rue, J. Woodgett, and S. Dedhar. 1998. Phosphoinositide-3-OH kinase-dependent regulation of glycogen synthase kinase 3 and protein kinase B/Akt by the integrin-linked kinase. Proc. Natl. Acad. Sci. 95: 11211-11216

Deprez, J., D. Vertommen, D.R. Alessi, L. Hue, and M.H. Rider. 1997. Phosphorylation and activation of heart 6-phosphofructo-2-kinase by protein kinase $\mathrm{B}$ and other protein kinases of the insulin signaling cascades. J. Biol. Chem. 272: 1726917275.

Deshmukh, M. and E.M. Johnson, Jr. 1998. Evidence of a novel event during neuronal death: Development of competenceto-die in response to cytoplasmic cytochrome C. Neuron 21: 695-705.

Diaz-Meco, M.T., M.M. Municio, S. Frutos, P. Sanchez, J. Lozano, L. Sanz, and J. Moscat. 1996. The product of par-4, a gene induced during apoptosis, interacts selectively with the atypical isoforms of protein kinase C. Cell 86: 777-786.

Dickens, M., C.A. Svitek, A.A. Culbert, R.M. O'Brien, and J.M. Tavare. 1998. Central role for phosphatidylinositide 3-kinase in the repression of glucose-6-phosphatase gene transcription by insulin. J. Biol. Chem. 273: 20144-20149.

Dimmeler, S., I. Fleming, B. Fisslthaler, C. Hermann, R. Busse, and A.M. Zeiher. 1999. Activation of nitric oxide synthase in endothelial cells by Akt-dependent phosphorylation. Nature 399: 601-605.

Dockrell, D.H., A.D. Badley, J.S. Villacian, C.J. Heppelmann, A. Algeciras, S. Ziesmer, H. Yagita, D.H. Lynch, P.C. Roche, P.J. Leibson et al. 1998. The expression of Fas Ligand by 
macrophages and its upregulation by human immunodeficiency virus infection. J. Clin. Invest. 101: 2394-2405.

Dong, L.Q., R-b. Zhang, P. Langlais, H. He, M. Clark, L. Zhu, and F. Liu. 1999. Primary structure, tissue distribution, and expression of mouse phosphoinositide-depnednt protein kinase-1, a protein kinase that phosphorylates and activates

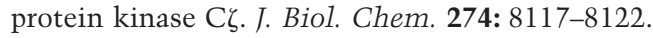

Dragovich, T., C.M. Rudin, and C.B. Thompson. 1998. Signal transduction pathways that regulate cell survival and cell death. Oncogene 17: 3207-3213.

$\mathrm{Du}, \mathrm{K}$. and M. Montminy. 1998. CREB is a regulatory target for the protein kinase Akt/PKB. I. Biol. Chem. 273: 3237732379.

Dudek, H., S.R. Datta, T.F. Franke, M.J. Birnbaum, R. Yao, G.M. Cooper, R.S. Segal, D.R. Kaplan, and M.E. Greenberg. 1997. Regulation of neuronal survival by the serine-threonine protein kinase Akt. Science 275: 661-665.

el-Deiry, W.S., T. Tokino, V.E. Velculescu, D.B. Levy, R. Parsons, J.M. Trent, D. Lin, W.E. Mercer, K.W. Kinzler, and B. Vogelstein. 1993. WAF1, a potential mediator of p53 tumor suppression. Cell 75: 817-825.

Eves, E.M., W. Xiong, A. Bellacosa, S.G. Kennedy, P.N. Tsichlis, M.R. Rosner, and N. Hay. 1998. Akt, a target of phosphatidylinositol 3-kinase, inhibits apoptosis in a differentiating neuronal cell line. Mol. Cell. Biol. 18: 2143-2152.

Faris, M., N. Kokot, K. Latinis, S. Kasibhatla, D.R. Green, G.A. Koretzky, and A. Nel. 1998. The c-Jun N-terminal kinase cascade plays a role in stress-induced apoptosis in Jurkat cells by up-regulating Fas ligand expression. I. Immunol. 160: $134-144$.

Filippa, N., C.L. Sable, C. Filloux, B. Hemmings, and E. Van Obberghen. 1999. Mechanism of protein kinase B activation by cyclic AMP-dependent protein kinase. Mol. Cell. Biol. 19: 4989-5000.

Foo, S.Y. and G.P. Nolan. 1999. NF-кB to the rescue: RELs, apoptosis and cellular transformation. Trends Genet. 15: 229-235.

Franke, T.F., K.D. Tartof, and P.N. Tsichlis. 1994. The SH2-like akt homology (AH) domain of c-akt is present in multiple copies in the genome of vertebrate and invertebrate eukaryotes. Cloning and characterization of the Drosophila melanogaster c-akt homolog Daktl. Oncogene 9: 141-148.

Franke, T.F., S.I. Yang, T.O. Chan, K. Datta, A. Kazlauskas, D.K. Morrison, D.R. Kaplan, and P.N. Tsichlis. 1995. The protein kinase encoded by the Akt proto-oncogene is a target of the PDGF-activated phosphatidlyinositol 3-kinase. Cell 81: 727-736.

Franke, T.F., D.R. Kaplan, L.C. Cantley, and A. Toker. 1997. Direct regulation of the Akt proto-oncogene product by phosphatidylinositol-3,4-bisphosphate. Science 275: 665668.

Frech, M., M. Andjelkovic, E. Ingley, K.K. Reddy, J.R. Falck, and B.A. Hemmings. 1997. High affinity binding of inositol phosphates and phosphoinositides to the pleckstrin homology domain of RAC/protein kinase B and their influence on kinase activity. J. Biol. Chem. 272: 8474-8481.

Fruman, D.A., S.B. Snapper, M.Y. Claudine, L. Davidson, J.Y. Yu, F.W. Alt, and L.C. Cantley. 1999. Impaired B cell development and proliferation in absence of phosphoinositide 3-kinase p85 $\alpha$. Science 283: 393-397.

Fulton, D., J.P. Gratton, T.J. McCabe, J. Fontana, Y. Fujio, K. Walsh, T.F. Franke, A. Papapetropoulos, and W.C. Sessa. 1999. Regulation of endothelium-derived nitric oxide production by the protein kinase Akt. Nature 399: 577-601.

Galli, C., O. Meucci, A. Scorziello, T.M. Werge, P. Calissano, and G. Schettini. 1995. Apoptosis in cerebellar granule cells is blocked by high $\mathrm{KCl}$, forskolin, and IGF-1 through distinct mechanisms of action: The involvement of intracellular calcium and RNA synthesis. J. Neurosci. 15: 1172-1179.

Gerber, H.-P., A. McMurtrey, J. Kowalski, M. Yan, B.A. Keyt, V. Dixit, and N. Ferrara. 1998. Vascular endothelial growth factor regulates endothelial cell survival though the phospatidylinositol 3'-kinase/akt signal transduction pathway. $I$. Biol. Chem. 273: 30336-30343.

Gibson, S., S. Tu, R. Oyer, S.M. Anderson, and G.L. Johnson. 1999. Epidermal growth factor protects epithelial cells against fas-induced apoptosis. Requirement for Akt activation. J. Biol. Chem. 274: 17612-17618.

Goswami, R., R. Lacson, E. Yang, R. Sam, and T. Unterman. 1994. Functional analysis of glucocorticoid and insulin response sequences in the rat insulin-like growth factor-binding protein-1 promoter. Endocrinology 134: 736-743.

Green, D.R. 1998. Apoptotic pathways: The roads to ruin. Cell 94: 695-698.

Green, D.R. and J.C. Reed. 1998. Mitochondria and apoptosis. Science 281: 1309-1312.

Gu, J., M. Tamura, and K.M. Yamada. 1998. Tumor suppressor PTEN inhibits integrin- and growth factor-mediated mitogen-activate protein (MAP) kinase signaling pathways. $J$. Cell. Biol. 143: 1375-1383.

Guo, S., G. Rena, S. Cichy, X. He, P. Cohen, and T. Unterman. 1999. Phosphorylation of serine 256 by protein kinase B disrupts transactivation by FKHR and mediates effects of insulin on IGF binding protein-1 promoter activity through a conserved insulin response sequence. J. Biol. Chem. 274: $17184-17192$.

Hajduch, E., D.R. Alessi, B.A. Hemmings, and H.S. Hundal. 1998. Constitutive activation of protein kinase $\mathrm{B} \alpha$ by membrane targeting promotes glucose and system A amino acid transport, protein synthesis and inactivation of glycogen synthase kinase-3 in L6 muscle cells. Diabetes 47: 10061013.

Hanks, S.K., A.M. Quinn, and T. Hunter. 1988. The protein kinase family-conserved features and deduced phylogeny of the catalytic domains. Science 241: 42-52.

Harada, H., B. Becknell, M. Wilm, M. Mann, L.J-S Huang, S.S. Taylor, J.D. Scott, and S.J. Korsmeyer. 1999. Phosphorylation and inactivation of $\mathrm{BAD}$ by mitochondria-anchored protein kinase A. Mol. Cell 3: 413-422.

Hausler, P., G. Papoff, A. Eramo, K. Reif, D.A. Cantrell, and G. Ruberti. 1998. Protection of CD95-mediated apoptosis by activation of phosphatidylinositide 3-kinase and protein kinase b. Eur. J. Immunol. 28: 57-69.

Helgason, C.D., J.E. Damen, P. Rosten, R. Grewal, P. Sorenson, S.M. Chappel, A. Borowski, F. Jirik, G. Krystal, and R.K. Humphries. 1998. Targeted disruption of SHIP leads to hematapoetic perturbations, lung pathology and a shortened life span. Genes \& Dev. 12: 1610-1620.

Hillion, J., M. Le Coniat, P. Jonveaux, R. Berger, and O.A. Bernard. 1997. AF6q21, a novel partner of the MLL gene in $\mathrm{t}(6 ; 11)(\mathrm{q} 21 ; \mathrm{q} 23)$, defines a forkhead transcriptional factor subfamily. Blood 90: 3714-3719.

Horvitz, H.R. 1999. Genetic control of programmed cell death in the nematode Caenorhabditis elegans. Cancer Res. 59: 1701-1706.

James, S.R., C.P. Downes, R. Gigg, S.J.A. Grove, A.B. Holmes, and D.R. Alessi. 1996. Specific binding of the Akt-1 protein kinase to phospatidylinositol 3,4,5-trisphosphate without subsequent activation. Biochem. J. 315: 709-713.

Jones, P.F., T. Jakubowicz, F.J. Pitossi, F. Maurer, and B.A. Hemmings. 1991. Molecular cloning and identification of a serine/threonine protein kinase of the second messenger sub- 
family. Proc. Nat1. Acad. Sci. 88: 4171-4175.

Juin, P., A.O. Hueber, T. Littlewood, and G. Evan. 1999. c-myc induced sensitization to apoptosis is mediated through cytochrome c release. Genes \& Dev. 13: 1367-1381.

Kaipia, A., S.Y. Hsu, and A.J.W. Huseh. 1997. Expression and function of a proapoptotic Bcl-2 family member Bcl-Xl/Bcl2-associated death promoter (BAD) in rat ovary. Endocrin. 138: 5497-5504.

Kane, L.P., V.S. Shapiro, D. Stokoe, and A. Weiss. 1999. Induction of NF-кB by the Akt/PKB kinase. Curr. Biol. 9: 601-604.

Kang, S.S., T. Kwon, D.Y. Kwon, and S.I. Do. 1999. Akt protein kinase enhances human telomerase activity through phosphorylation of telomerase reverse transcriptase subunit. $J$. Biol. Chem. 274: 13085-13090.

Kauffmann-Zeh, A., P. Rodriguez-Vicana, E. Ulrich, C. Gilbert, P. Coffer, J. Downward, and G. Evan. 1997. Suppression of c-Myc-induced apoptosis by Ras signalling through PI(3)K and PKB. Nature 385: 544-548.

Kennedy, S.G., A.J. Wagner, S.D. Conzen, J. Jordan, A. Bellacosa, P.N. Tsichlis, and N. Hay. 1997. The PI3-Kinase/Akt signaling pathway delivers an anti-apoptotic signal. Genes \& Dev. 11: 701-713.

Kennedy, S.G., E.S. Kandel, T.K. Cross, and N. Hay. 1999. Akt/ PKB inhibits cell death by preventing the release of cytochrome c from mitochondria. Mol. Cell. Biol. 19: 5800-5810.

Khwaja, A. 1999. Akt is more than just a Bad kinase. Nature 401: $33-34$

Khwaja, A. and J. Downward. 1997. Lack of correlation between activation of Jun-NH2-terminal kinase and induction of apoptosis after detachment of epithelial cells. J. Cell. Biol. 139: 1017-1023.

Khwaja, A., P. Rodriguez-Vicana, S. Wennstrom, P.H. Warne, and J. Downward. 1997. Matrix adhesion and Ras transformation both activate a phosphoinositide 3-OH kinase and protein kinase B/Akt cellular survival pathway. EMBO $J$. 16: $2783-2793$.

Kimura, K.D., H.A. Tissenbaum, Y. Liu, and G. Ruvkun. 1997. daf-2, an insulin receptor-like gene that regultes longevity in diapause in Caenorhabiditis elegans. Science 277: 942-946.

King, W.G., M.D. Mattaliano, T.O. Chan, P.N. Tsichlis, and J.S. Brugge. 1997. Phosphatidylinositol 3-kinase is required for integrin-stimulated AKT and Raf-1/mitogen-activated protein kinase pathway activation. Mol. Cell. Biol. 17: 44064418.

Kitada, S., M. Krajewksa, X. Zhang, D. Scudiero, J.M. Zapata, H.-G. Wang, A. Shabaik, G. Tudor, S. Krajewski, T.G. Myers et al. 1998. Expression and location of pro-apoptotic Bcl-2 family protein BAD in normal human tissues and tumor cells lines. Am. J. Path. 152: 51-61.

Kitamura, T., W. Ogawa, H. Sakaue, Y. Hino, S. Kuroda, M. Takata, M. Matsumoto, T. Maeda, H. Konishi, U. Kikkawa et al. 1998a. Requirement for activation of the serine-threonine kinase Akt (PKB) in insulin stimulation of protein synthesis but not of glucose transport. Mol. Cell. Biol. 18: 37083717.

Kitamura, Y., S. Simohama, W. Kamoshima, T. Ota, Y. Matsuoka, T. Nomura, M.A. Smith, G. Perry, P.J. Whitehouse, and T. Taniguchi. 1998b. Alteration of proteins regulating apoptosis, Bcl-2, Bcl-x, Bax, Bak, Bad, ICH-1 and CPP32 in Alzheimer's disease. Brain Res. 780: 260-269.

Klippel, A., C. Reinhard, W.M. Kavanaugh, G. Apell, M-A. Escobedo, and L.T. Williams. 1996. Membrane localization of phosphatidylinositol 3-kinase is sufficient to activate multiple signal-transduction kinase pathways. Mol. Cell. Biol. 16: 4117-4127.

Klippel, A., W.M. Kavanaugh, D. Pot, and L.T. Williams. 1997.
A specific product of phosphatidylinositol 3-kinase directly activates the protein kinase akt through its pleckstrin homology domain. Mol. Cell. Biol. 17: 338-344.

Kohn, A.D., S.A. Summers, M.J. Birnbaum, and R.A. Roth. 1996a. Expression of a constitutively active Akt ser/thr kinase in 3T3-L1 adipocytes stimulates glucose uptake and glucose transporter 4 translocation. J. Biol. Chem. 271: 31372-31378.

Kohn, A.D., F. Takeuchi, and R.A. Roth. 1996b. Akt, a pleckstrin homology domain containing kinase, is activated primarily by phosphorylation. J. Biol. Chem. 271:2192021926.

Kohn, A.D., A. Barthel, K.S. Kovacina, A. Boge, B. Wallach, S.A. Summers, M.J. Birnbaum, P.H. Scott, J.C. Lawrence, Jr., and R.A. Roth. 1998. Construction and characterization of a conditionally active version of the serine/threonine kinase akt. J. Biol. Chem. 273: 11937-11943.

Kops, G.J., N.D. de Ruiter, A.M. De Vries-Smits, D.R. Powell, J.L. Bos, and B.M. Burgering. 1999. Direct control of the Forkhead transcription factor AFX by protein kinase B. Nature 398: 630-634.

Konishi, H., S. Kuroda, M. Tanaka, H. Matsuzaki, Y. Ono, K. Kameyama, T. Haga, and U. Kikkawa. 1995. Molecular cloning and characterization of a new member of the RAC protein kinase family: Association of the pleckstrin homology domain of three types of RAC protein kinase with protein kinase $\mathrm{C}$ subspecies and beta gamma subunits of $\mathrm{G}$ proteins. Biochem. Biophys. Res. Comm. 216: 526-534.

Kulik, G. and M.J. Weber. 1998. Akt-dependent and independent survival signaling pathways utilized by insulin-like growth factor 1. Mol. Cell. Biol. 18: 6711-6718.

Kulik, G., A. Klippel, and M.J. Weber. 1997. Antiapoptotic signalling by the insulin-like growth factor 1 receptor, phosphatidylinositol 3-kinase, and Akt. Mol. Cell. Biol. 17: 15951606.

Kurada, P. and K. White. 1998. Ras promotes cell survival in Drosophila by downregulating hid expression. Cell 95: 319329.

Le-Niculescu, H., E. Bonfoco, Y. Kasuya, F.X. Claret, D.R. Green, and M. Karin. 1999. Withdrawal of survival factors results in activation of the JNK pathway in neuronal cells leading to Fas Ligand induction and cell death. Mol. Cell. Biol. 19: 751-763.

Levi-Montalcini, R. 1987. The nerve growth factor 35 years later. Science 237: 1154-1162.

Li, J., C. Yen, D. Liaw, K. Podsypanina, S. Bose, S.I. Wang, J. Puc, C. Miliaresis, L. Rodgers, R. McCombie et al. 1997. PTEN, a putative protein tyrosine phosphatase gene mutated in human brain, breast, and prostate cancer. Science 28: 19431947.

Li, W.W., M.M. Dammerman, J.D. Smith, S. Metzger, J.L. Breslow, and T. Leff. 1995. Common genetic variation in the promoter of the human apo CIII gene abolishes regulation by insulin and may contribute to hypertriglyceridemia. J. Clin. Invest. 96: 2601-2605.

Li-Weber, M., O. Laur, A. Hekele, J. Coy, H. Walczak, and P.H. Krammer. 1998. A regulatory element in the CD95 (APO-1) Fas) ligand promoter is essential for responsiveness to TCRmediated activation. Eur. I. Immunol. 28: 2373-2383.

Liao, J., A. Barthel, K. Nakatani, and R.A. Roth. 1998. Activation of protein kinase B/Akt is sufficient to repress the glucocorticoid and cAMP induction of phosphoenolpyruvate carboxykinase gene. J. Biol. Chem. 273: 27320-27324.

Liaw, D., D.J. Marsh, J. Li, P.L. Dahia, S.I. Wang, Z. Zheng, S. Bose, K.M. Call, H.C. Tsou, M. Peacocke et al. 1997. Germline mutations of the PTEN gene in Cowden disease, an in- 
herited breast and thyroid cancer syndrome. Nat. Genet. 16: 64-67.

Lin, K., J.B. Dorman, A. Rodan, and C. Kenyon. 1997. daf-16: An HNF-3/forkhead family member that can function to double the life-span of Caenorhabditis elegans. Science 278: 13191322.

Liu, L., J.E. Damen, M.R. Hughes, I. Babic, F.R. Jirik, and G. Krystal. 1997. The src homology 2 (SH2) domain of SH2containing inositol phosphatase (SHIP) is essential for tyrosine phosphorylation of SHIP, its association with shc, and its induction of apoptosis. J. Biol. Chem. 272: 8983-8988.

Liu, Q., T. Sasaki, I. Kozieradzki, D.J. Dumont, and J.M. Penninger. 1999. SHIP is a negative regulator of growth factor receptor-mediated PKB/Akt activation and myeloid cell survival. Genes \& Dev. 13: 786-791.

Liu, X.-X., J.R. Testa, T.C. Hamilton, R. Jove, S.V. Nicosia, and J.Q. Cheng. 1998. Akt2, a member of the protein kinase B family, is activated by growth factors, v-Ha-ras, and v-src through a phosphatidylinositol 3-kinase in human ovarian epithelial cancer cells. Cancer Res. 58: 2973-2977.

Lopez-Girona, A., B. Furnari, O. Mondesert, and P. Russell. 1999. Nuclear localization of Cdc25 is regulated by DNA damage and a 14-3-3 protein. Nature 397: 172-155.

Maehama, T. and J.E. Dixon. 1998. The tumor suppressor, PTEN/MMAC1, dephosphorylates the lipid second messenger, phosphatidylinositol 3,4,5-trisphosphate. J. Biol. Chem. 273: $13375-13378$.

Marsh, D.J., V. Coulon, K.L. Lunetta, P. Rocca-Serra, P.L. Dahia, Z. Zheng, D. Liaw, S. Caron, B. Duboue, A.Y. Lin et al. 1998. Mutation spectrum and genotype-phenotype analyses in Cowden disease and Bannayan-Zonana syndrome, two hamartoma syndromes with germline PTEN mutation. Hum. Mol. Genet. 7: 507-515.

Marte, B.M., P. Rodriguez-Viciana, S. Wennstrom, P.H. Warne, and J. Downward. 1996. R-Ras can activate the phosphoinositide 3-kinase but not the MAP kinase arm of ras effector pathways. Curr. Biol. 7: 63-70.

May, M.J. and S. Ghosh. 1997. Rel/ NF-кB and ІкB proteins: An overview. Semin. Cancer Biol. 8: 63-73.

Mayer, B.J., R. Ren, K.L. Clark, and D. Baltimore. 1993. A putative modular domain present in diverse signalling proteins. Cell 73: 629-630.

Mazure, N.M., E.Y. Chen, K.R. Laderoute, and A.J. Giaccia. 1997. Induction of vascular endothelial growth factor by hypoxia is modulated by a phosphatidylinositol 3-kinase/ Akt signaling pathway in Ha-ras-transformed cells through a hypoxia inducible factor-1 transcriptional element. Blood 90: 3322-3331.

Meier, P. and G. Evan. 1998. Dying like flies. Cell 9: 295-298.

Meier, R., D.R. Alessi, P. Cron, M. Andjelkovic, and B.A. Hemmings. 1997. Mitogenic activation, phosphorylation and nuclear translocation of protein kinase $\mathrm{B} \beta$. J. Biol. Chem. 272: 30491-30497.

Mercurio, F. and A.M. Manning. 1999. Multiple signals converging on NF-кB. Curr. Biol. 11: 226-232.

Meyer-Franke, A., M.R. Kaplan, F.W. Pfrieger, and B.A. Barres. 1995. Characterization of the signaling interactions that promote the survival and growth of developing retinal ganglion cells in culture. Neuron 15: 805-819.

Miho, Y., Y. Kouroku, E. Fujita, T. Mukasa, K. Urase, T. Kasahara, A. Isoai, M.Y. Momoi, and T. Momoi. 1999. bFGF inhibits the activation of caspase-3 and apoptosis of P19 embyonal carcinoma cells during neuonal differentiation. Cell Death Diff. 6: 463-470.

Miller, T.M. and E.M. Johnson, Jr. 1996. Metabolic and genetic analyses of apoptosis in potassium/serum-deprived rat cer- ebellar granule cells. J. Neurosci. 16: 7487-7495.

Miyashita, T. and J.C. Reed. 1995. Tumor suppressor p53 is a direct transcriptional activator of the human bax gene. Cell 80: 293-299.

Miyashita, T., S. Krajewski, M. Krajewska, H.G. Wang, H.K. Lin, D.A. Liebermann, B. Hoffman, and J.C. Reed. 1994. Tumor suppressor p53 is a regulator of bcl-2 and bax gene expression in vitro and in vivo. Oncogene 9: 1799-1805.

Mok, C.L., G. Gil-Gomez, O. Williams, M. Coles, S. Taga, M. Tolaini, T. Norton, D. Kioussis, and H.J.M. Brady. 1999. Bad can act as a key regulator of $\mathrm{T}$ cell apoptosis and $\mathrm{T}$ cell development. J. Exp. Med. 189: 575-586.

Morris, J.Z., H.A. Tissenbaum, and G. Ruvkun. 1996. A phosphotidylinositol-3-OH kinase family member regulating longevity and diapause in Caenorhabditis elegans. Nature 382: 536-539.

Murga, C., L. Laguinge, R. Wetzker, A. Cuadrado, and J.S. Gutkind. 1998. Activation of Akt/protein kinase b by G proteincoupled receptors. J. Biol. Chem. 273: 19080-19085.

Musacchio, A., T. Gibson, P. Rice, J. Thompson, and M. Saraste. 1993. The PH domain: A common piece in the structural pathwork of signaling proteins. Trends Biochem. Sci. 18: 343-348.

Muslin, A.J., J.W. Tanner, P.M. Allen, and A.S. Shaw. 1996. Interaction of 14-3-3 with signaling proteins is mediated by the recognition of phosphoserine. Cell 84: 889-897.

Myers, M.P., I. Pass, I.H. Batty, J. Van der Kaay, J.P. Stolarov, B.A. Hemmings, M.H. Wigler, C.P. Downes, and N.K. Tonks. 1998. The lipid phosphatase activity of PTEN is critical for its tumor suppressor function. Proc. Natl. Acad. Sci. 95: $13513-13518$.

Nagata, S. 1997. Apoptosis by death factor. Cell 88: 355-365.

Nakae, J., B.C. Park, and D. Accili. 1999. Insulin stimulates phosphorylation of the forkhead transcription factor FKHR on serine 253 through a wortmannin-sensitive pathway. I. Biol. Chem. 274: 15982-15985.

Nakatani, K., H. Sakaue, D.A. Thompson, R.J. Weigel, and R.A. Roth. 1999. Identification of a human Akt3 (protein kinase B $\gamma$ ) which contains the regulatiory serine phosphorylation. Biochem. Biophys. Res. Comm. 257: 906-910.

Nelen, M.R., W.C. van Staveren, E.A. Peeters, M.B. Hassel, R.J. Gorlin, H. Hamm, C.F. Lindboe, J.P. Fryns, R.H. Sijmons, D.G. Woods et al. 1997. Germline mutations in the PTEN/ MMAC1 gene in patients with Cowden disease. Hum. Mol. Genet. 6: 1383-1387.

Nishida, K., Y. Kaziro, and T. Satoh. 1998. Anti-apoptotic function of rac in hematopoietic cells. Oncogene 18: 407-415.

Nobes, C. and A. Tolkovsky. 1995. Neutralizing anti-p21 Ras Fabs suppress rat sympathetic neuron survival induced by NGF, LIF, CNTF and cAMP. Eur. J. Neurosci. 7: 344-350.

O'Brien, R.M., P.C. Lucas, C.D. Forest, M.A. Magnuson, and D.K. Granner. 1990. Identification of a sequence in the PEPCK gene that mediates a negative effect of insulin on transcription. Science 249: 533-537.

Ogg, S., S. Paradis, S. Gottlieb, G.I. Patterson, L. Lee, H.A. Tissenbaum, and G. Ruvkun. 1997. The Fork head transcription factor DAF-16 transduces insulin-like metabolic and longevity signals in C. elegans. Nature 389: 994-999.

Ottilie, S., J-L. Diaz, W. Horne, J. Chang, Y. Wang, G. Wilson, S. Chang, S. Weeks, L. Fritz, and T. Oltersdorf. 1997. Dimerization properties of human Bad: Identification of a $\mathrm{BH}-3$ domain and analysis of its binding to mutant Bcl-2 and BclXl proteins. J. Biol. Chem. 272: 30866-30872.

Ozes, O.N., L.D. Mayo, J.A. Gustin, S.R. Pfeffer, L.M. Pfeffer, and D.B. Donner. 1999. NF-кB activation by tumour necrosis factor requires the Akt serine-threonine kinase. Nature 
401: 82-85.

Pap, M. and G.M. Cooper. 1998. Role of glycogen synthase kinase-3 in the phosphatidylinositol 3-kinase/akt cell survival pathway. J. Biol. Chem. 273: 19929-19932.

Paradis, S. and G. Ruvkun. 1998. Caenorhabditis elegans Akt/ PKB transduces insulin receptor-like sugnals from AGE-1 PI3 kinase to the DAF-16 transcription factor. Genes \& Dev. 12: $2488-2498$.

Paradis, S., M. Ailion, A. Toker, J.H. Thomas, and G. Ruvkun. 1999. A PDK1 homolog is necessary and sufficient to transduce AGE-1 PI3 kinase signals that regulate diapause in caenorhabditis elegans. Genes \& Dev. 13: 1438-1452.

Parrizas, M., A.R. Saltiel, and D. LeRoith. 1997. Insulin-like growth factor 1 inhibits apoptosis using the phosphatidylinositol 3-kinase and mitogen-activated protein kinase pathways. J. Biol. Chem. 272: 154-161.

Pettmann, B. and C.E. Henderson. 1998. Neuronal cell death. Neuron 20: 633-647.

Philpott, K.L., M.J. McCarthy, A. Klippel, and L.L. Rubin. 1997. Activated phosphatidylinositol 3-kinase and akt kinase promote survival of superior cervical neurons. I. Cell Biol. 139: 809-815.

Powell, D.R., S.V. Allander, A.O. Scheimann, R.M. Wasserman, S.K. Durham, and A. Suwanichkul. 1995. Multiple proteins bind the insulin response element in the human IGFBP-1 promoter. Prog. Growth Factor Res. 6: 93-101.

Pugazhenthi, S., T. Boras, D. O'Connor, M.K. Meinter, K.A. Heidenreich, and J.E. Reusch. 1999. Insulin-like growth factor I-mediated activation of the transcription factor cAMP response element-binding protein in PC12 cells. Involvement of p38 mitogen-activating protein kianse-mediated pathway. J. Biol. Chem. 274: 2829-2837.

Rameh, L.E. and L.C. Cantley. 1999. The role of phosphoinositide-3-kinase lipid products in cell function. J. Biol. Chem. 274: 8347-8350.

Reed, J.C. 1998. Bcl-2 family proteins. Oncogene 17: 3225-3236.

Rena, G., S. Guo, S. Cichy, T.G. Unterman, and P. Cohen. 1999. Phosphorylation of the transcription factor forkhead family member FKHR by protein kinase B. J. Biol. Chem. 274: 17179-17183.

Rhoades, K.L., S.H. Golub, and J.S. Economou. 1992. The regulation of the human tumor necrosis factor alpha promoter region in macrophage, T cell, and B cell lines. J. Biol. Chem. 267: 22102-22107.

Rodriguez-Viciana, P., P.H. Warne, R. Dhand, R., B. Vanhaesebroeck, I. Gout, M.J. Fry, M.D. Waterfield, and J. Downward. 1994. Phosphatidylinositol-3-OH kinase as a direct target of Ras. Nature 370: 527-532.

Rodriguez-Viciana, P., P.H. Warne, B. Vanhaesebroeck, M.D. Waterfield, and J. Downward. 1996. Activation of phosphoinositide 3-kinase by interaction with Ras and by point mutation. EMBO J. 15: 2442-2451.

Rohn, J.L., A-O. Hueber, N.J. McCarthy, D. Lyon, P. Navarro, B.M.T. Burgering, and G.I. Evan. 1998. The opposing roles of the Akt and c-Myc signalling pathways in survival from CD95-mediated apoptosis. Oncogene 17: 2811-2828.

Romanshkova, J.A. and S.S. Makarov. 1999. NF-кB is a target of Akt in anti-apoptotic PDGF signaling. Nature 401: 86-89.

Sable, C.L., N. Filippa, B. Hemmings, and E. Van Obberghen. 1997. cAMP stimulates protein kinase B in a wortmannininsensitive manner. FEBS Lett. 409: 253-257.

Sable, C.L., N. Filippa, C. Filloux, B.A. Hemmings, and E. van Obberghen. 1998. Involvement of the pleckstrin homology domain in the insulin-stimulated activation of protein kinase B. J. Biol. Chem. 273: 29600-29606.

Scheid, M.P. and V. Duronio. 1998. Dissociation of cytokine- induced phosphorylation of Bad and activation of PKB/akt: Involvement of MEK upstream of Bad phosphorylation. Proc. Nat1. Acad. Sci. 95: 7439-7444.

Scheid, M.P., R.W. Lauener, and V. Duronio. 1995. Role of phosphatidylinositol 3-OH-kinase activity in the inhibition of apoptosis in haemopoetic cells: Phosphatidylinositol 3-OH kinase inhibitors reveal a difference in signalling between interleukin-3 and granulocyte-macrophage colony stimulating factor. Biochem. J. 312: 159-162.

Segal, R.A. and M.E. Greenberg. 1996. Intracellular signaling pathways activated by neurotrophic factors. Annu. Rev. Neurosci. 19: 463-489.

Shaw, M., P. Cohen, and D.R. Alessi. 1997. Further evidence that the inhibition of glycogen synthase kinase-3 $\beta$ by IGF-1 is mediated by PDK1/PKB-induced phosphorylation of ser-9 and not by dephosphorylation of tyr-126. FEBS Lett. 416: 307-311.

Shieh, P.B., S.C. Hu, K. Bobb, T. Timmusk, and A. Ghosh. 1998. Identification of a signaling pathway involved in calcium regulation of BDNF expression. Neuron 20: 727-740.

Shimamura, A., B.A. Ballif, S.A. Richards, and J. Blenis. 1999. RSK phosphorylation of BAD mediates a MAP kinase survival pathway. Submitted.

Skorski, T., A. Bellacosa, M. Nieborowska-Skorska, M. Majewski, R. Martinez, J.K. Choi, R. Trotta, P. Wlodarski, D. Perrotti, T.O. Chan et al. 1997. Transformation of hematopoietic cells by BCR/ABL requires activation of a PI-3k/Aktdependent pathway. EMBO J. 16: 6151-6161.

Sonenshein, G.E. 1997. Rel/ NF-кB transcription factors and the control of apoptosis. Trends Can. Biol. 8: 113-119.

Songyang, Z., D. Baltimore, L.C. Cantley, D.R. Kaplan, and T.F. Franke. 1997. Interleukin 3-dependent survival by the Akt protein kinase. Proc. Nat. Acad. Sci. 94: 11345-11350.

Soskic, V., M. Gorlach, S. Poznanovic, F.D. Boehmer, and J. Godovac-Zimmermann. 1999. Functional proteomics analysis of signal transduction pathways of the platelet-derived growth factor beta receptor. Biochemistry 38: 1757-1764.

Srinivasula, S.M., M. Ahmad, T. Fernandes-Alnemri, and E.S. Alnemri. 1998. Autoactivation of procaspase-9 by Apaf-1mediated oligomerization. Mol. Cell 1: 949-957.

Staal, S.P. 1987. Molecular cloning of the akt oncogene and its human homologs Akt1 and Akt2: Amplification of Akt1 in a primary human gastric adenocarcinoma. Proc. Natl. Acad. Sci. 84: 5034-5037.

Staal, S.P., J.W. Hartley, and W.P. Rowe. 1977. Isolation of transforming murine leukemia viruses from mice with a high incidence of spontaneous lymphoma. Proc. Natl. Acad. Sci. 74: 3065-3067.

Stambolic, V., A. Suzuki, J.L. de la Pompa, G.M. Brothers, C. Mirtsos, T. Sasaki, J. Ruland, J.M. Penninger, D.P. Sioderovski, and T.W. Mak. 1998. Negative regulation of PKB/ Akt-dependent cell survival by the tumor suppressor PTEN. Cell 95: 29-39.

Staveley, B.E., L. Ruel, J. Jin, V. Stambolic, F.G. Mastronardi, P. Heizler, J.R. Woodgett, and A.S. Manoukian. 1998. Genetic analysis of protein kinase B (AKT) in Drosophila. Curr. Biol. 8: 599-602.

Stephens, L., K. Anderson, D. Stokoe, H. Erdjument-Bromage, G.F. Painter, A.B. Holmes, P.R.J. Gaffney, C.B. Reese, F. McCormick, P. Tempst et al. 1998. Protein kinase b kinase that mediate phosphatidylinositol 3,4,5-trisphosphate-dependent activation of protein kinase b. Science 279: 710-714.

Stokoe, D., L.R. Stephens, T. Copeland, P.R.J. Gaffney, C.B. Reese, G.F. Painter, A.B. Holmes, F. McCormick, and P.T. Hawkins. 1997. Dual role of phosphatidylinositol-3,4,5-trisphosphate in the activation of protein kinase B. Science 
277: 567-570.

Streeper, R.S., C.A. Svitek, S. Chapman, L.E. Greenbaum, R. Taub, and R.M. O'Brien. 1997. A multicomponent insulin response sequence mediates a strong repression of mouse glucose-6-phosphatase gene transcription by insulin. J. Biol. Chem. 272: 11698-11701.

Sublett, J.E., I.S. Jeon, and D.N. Shapiro. 1995. The alveolar rhabdomyosarcoma PAX3/FKHR fusion protein is a transcriptional activator. Oncogene 11: 545-552.

Summers, S.A., L.A. Garza, H. Zhou, and M.J. Birnbaum. 1998. Regulation of insulin-stimulated glucose transporter GLUT4 translocation and akt kinase activity by ceramide. Mol. Cell. Biol. 18: 5457-5464.

Sung, S.J., J.A. Walters, J. Hudson, and J.M. Gimble. 1991. Tumor necrosis factor-alpha mRNA accumulation in human myelomonocytic cell lines. Role of transcriptional regulation by DNA sequence motifs and mRNA stabilization. $J$. Immunol. 147: 2047-2054.

Sutherland, C., R.M. O'Brien, and D.K. Granner. 1995. Phosphatidylinositol 3-kinase, but not $\mathrm{p} 70 / \mathrm{p} 85$ ribosomal S6 protein kinase, is required for the regulation of phosphoenolpyruvate carboxykinase (PEPCK) gene expression by insulin. Dissociation of signaling pathways for insulin and phorbol ester regulation of PEPCK gene expression. J. Biol. Chem. 270: 15501-15506.

Suwanickul, A., S.L. Morris, and D.R. Powell. 1993. Identification of an insulin-responsive element in the promoter of the human gene for insulin-like growth factor binding protein-1. J. Biol. Chem. 268: 17063-17068.

Suzuki, A., J.L. de la Pompa, V. Stambolic, A.J. Elia, T. Sasaki, I. del Barco Barrantes, A. Ho, A. Wakeham, A. Itie, W. Khoo et al. 1998. High cancer susceptibility and embryonic lethality associated with mutation of the PTEN tumor suppressor gene in mice. Curr. Biol. 8: 1169-1178.

Takashima, A., K. Noguchi, G. Michel, M. Mercken, M. Hoshi, K. Ishiguro, and K. Imahori. 1996. Exposure of rat hippocampal neurons to amyloid beta peptide (25-35) induces the inactivation of phosphatidylinositol-3 kinase and the activation of tau protein kinase I/glycogen synthase kinase-3 beta. Neurosci. Lett. 203: 33-36.

Tang, D.G., L. Li, D.P. Chopra, and A.T. Porter. 1998. Extended survivability of prostate cancer cells in the absence of trophic factors: Increased proliferation, evasion of apoptosis, and the role of apoptosis proteins. Cancer Res. 58: 34663479.

Tang, E.D., G. Nuñez, F.G. Barr, and K.L. Guan. 1999. Negative regulation of the Forkhead transcription factor FKHR by Akt. J. Biol. Chem. 274: 16741-16746.

Tanti, J.-F., S. Grillo, T. Gremeaux, P.J. Coffer, E. van Obberghen, and Y. le Marchand-Brustel. 1997. Potential role of protein kinase B in glucose transporter 4 translocation in adipocytes. Endocrinology 138: 2005-2010.

Tao, X., S. Finkbeiner, D.B. Arnold, A.J. Shaywitz, and M.E. Greenberg. 1998. Ca2+ influx regulates BDNF transcription by a CREB family transcription factor-dependent mechanism. Neuron 20: 709-726.

Tilton, B., M. Andjelkovic, S.A. Didichenko, B.A. Hemmings, and M. Thelen. 1997. G-protein-coupled receptors and Fcgreceptors mediate activation of akt/protein kinase B in human phagocytes. J. Biol. Chem. 272: 28096-28101.

Toker, A. and L.C. Cantley. 1997. Signalling through the lipid products of phosphoinositide-3-OH kinase. Nature 387: 673-676.

Tsujimoto, Y. 1998. Role of Bcl-2 family proteins in apoptosis: Apoptosomes or mitochondria? Genes Cells 3: 697-707.

Ueki, K., R. Yamamoto-Honda, Y. Kaburagi, T. Yamauchi, K.
Tobe, B.M.T. Burgering, P.J. Coffer, I. Komuro, Y. Akanuma, Y. Yazaki et al. 1998. Potential role of protein kinase b in insulin-induced glucose transport, glycogen synthesis and protein synthesis. J. Biol. Chem. 273: 5315-5322.

Ulrich, E., A. Duwel, A. Kauffmann-Zeh, C. Gilbert, D. Lyon, B. Rudkin, G. Evan, and D. Martin-Zanca. 1998. Specific TrkA survival signals interfere with different apoptotic pathways. Oncogene 16: 825-832.

Unterman, T.G., A. Fareeduddin, M.A. Harris, R.G. Goswami, A. Porcella, R.H. Costa, and R.G. Lacson. 1994. Hepatocyte nuclear factor-3 (HNF-3) binds to the insulin response sequence in the IGF binding protein-1 (IGFBP-1) promoter and enhances promoter function Biochem. Biophys. Res. Commun. 203: 1835-1841.

van Weeren, P.C., K.M.T. de Bruyn, A.M.M. de Vries-Smits, J. van Lint, and B.M.T. Burgering. 1998. Essential role for protein kinase $\mathrm{B}(\mathrm{PKB})$ in insulin-induced glycogen synthase kinase 3 inactivation. J. Biol. Chem. 273: 13150-13156.

Vander Heiden, M.G., N.S. Chandel, P.T. Schumacker, and C.B. Thompson. 1999. Bcl-Xl prevents cell death following growth factor withdrawal by facilitating mitochondrial ATP/ADP exchange. Mol. Cell 3: 159-167.

Vaux, D.L. and S.J. Korsmeyer. 1999. Cell death in development. Cell 96: 245-254.

Vemuri, G.S. and F.A. McMorris. 1996. Oligodendrocytes and their precursors require phosphatidylinositol 3-kinase signaling for survival. Development 122: 2529-2537.

Walker, K.S., M. Deak, A. Paterson, K. Hudson, P. Cohen, and D.R. Alessi. 1998. Activation of protein kinase B beta and gamma isoforms by insulin in vivo and by 3 -phosphoinositide-dependent protein kinase-1 in vitro: Comparison with protein kinase B alpha. Biochem. J. 331: 229-308.

Wang, H.-G., U.R. Rapp, and J.C. Reed. 1996. Bcl-2 targets the protein kinase Raf-1 to mitochodria. Cell 87: 629-638.

Wang, H.-G., N. Pathan, I.M. Ethell, S. Krajewski, Y. Yamaguchi, F. Shibasaki, F. McKeon, T. Bobo, T.F. Franke, and J.C. Reed. 1999a. Ca2+-induced apoptosis through calcineurin dephosphorylation of Bad. Science 284: 339-343.

Wang, Q., R. Somwar, P.J. Bilan, Z. Liu, J. Jin, and J.R. Woodgett. 1999b. Protein kinase B/Akt participates in GLUT4 translocation by insulin in L6 myocytes. Mol. Cell. Biol. 19: 40084018.

Weiner, J.A. and J. Chun. 1999. Schwann cell survival mediated by the signaling phospholipid lysophosphatidic acid. Proc. Natl. Acad. Sci. 96: 5233-5238.

Widmann, C., S. Gibson, and G.L. Johnson. 1998. Caspase-dependent cleavage of signaling proteins during apoptosis. $I$. Biol. Chem. 273: 7141-7147.

Wijkander, J., L.S. Holst, T. Rahn, S. Resjo, I. Castan, V. Manganiello, P. Belfrage, and E. Degerman. 1997. Regulation of protein kinase $\mathrm{B}$ in rat adipocytes by insulin, vanadate and peroxyvanadate. J. Biol. Chem. 272: 21520-21526.

Wijkander, J., T.R. Landstrom, V. Manganiello, P. Belfrage, and E. Degerman. 1998. Insulin-induced phosphorylation and activation of phopshodiesterase 3B in rat adipocytes: Possible role for protein kinase B but not mitogen-activated protein kinase or p70 S6 kinase. Endocrinology 139: 219-227.

Xia, Z., M. Dickens, J. Raingeaud, R.J. Davis, and M.E. Greenberg 1995. Opposing effects of ERK and JNK-p38 MAP kinases on apoptosis. Science 270: 1326-1331.

Xiong, W.-C. and J.T. Parsons. 1997. Induction of apoptosis after expression of PYK2, a tyrosine kinase structurally related to focal adhesion kinase. J. Cell Biol. 139: 529-539.

Yaffe, M.B., K. Rittinger, S, Volinia, P.R. Caron, A. Aitken, H. Leffers, S.J. Gamblin, S.J. Smerdon, and L.C. Cantley. 1997. The structural basis for 14-3-3: Phosphopeptide binding 
specificity. Cell 91: 961-971.

Yang, E., J. Zha, J. Jockel, L.H. Boise, C.B. Thompson, and S.J. Korsmeyer. 1995. Bad, a heterodimeric partner for Bcl-Xl and Bcl-2, displaces Bax and promotes cell death. Cell 80: 285291.

Yano, S., H. Tokumitsu, and T.R. Soderling. 1998. Calcium promotes cell survival through CaM-K kinase activation of the protein-kinase B pathway. Nature 396: 584-587.

Yao, R. and Cooper, G.M. 1995. Requirement for phosphatidylinosotol-3 kinase in the prevention of apoptosis by nerve growth factor. Science 267: 2003-2006.

Zha, J., H. Harada, E. Yang, J. Jockel, and S.J. Korsmeyer. 1996. Serine phosphorylation of death agonist $\mathrm{BAD}$ is response to survival factor results in binding to 14-3-3 not BCL-XL. Cell 87: 619-628.

Zha, J., Harada, H., K. Osipov, J. Jockel, G. Waksmann, and S.J. Korsmeyer. 1997. $\mathrm{BH} 3$ domain of $\mathrm{Bad}$ is required for heterodimerization with $\mathrm{Bcl}-\mathrm{Xl}$ and pro-apoptotic activity. $J$. Biol. Chem. 272: 24101-24104.

Zhan, Q., S. Fan, I. Bae, C. Guillouf, D.A. Liebermann, P.M. O'Connor, and A.J. Fornace, Jr. 1994. Induction of bax by genotoxic stress in human cells correlates with normal p53 status and apoptosis. Oncogene 9: 3743-3751.

Zhang, X. and T.A. Vik. 1997. Growth factor stimulation of hematopoietic cells leads to membrane translocation of akt1 protein kinase. Leuk. Res. 21: 849-856.

Zhang, Z., H. Hartmann, V.M. Do, D. Abramowski, C. Sturchler-Pierrat, M. Staufenbiel, B. Sommer, M. van de Wetering, H. Clevers, P. Saftig et al. 1998. Destablization of beta-catenin by mutations in presenilin- 1 potentiates neuronal apoptosis. Nature 395: 698-702.

Zhou, H., S.A. Summers, M.J. Birnbaum, and R.N. Pittman 1998. Inhibition of Akt kinase by cell-permeable ceramide and its implications for ceramide-induced apoptosis. J. Biol. Chem. 273: 16568-16575.

Zong, W.-X., L.C. Edelstein, C. Chen, J. Bash, and C. Gelinas. 1999. The prosurvival Bcl-2 homolog Bfl-1/A1 is a direct transcriptional target of NF- $\mathrm{B}$ that blocks TNFa-induced apoptosis. Genes \& Dev. 13: 382-387.

Zundel, W. and A. Giaccia. 1998. Inhibition of the anti-apoptotic PI3K/Akt/Bad pathway by stress. Genes \& Dev. 12: 1941-1946. 


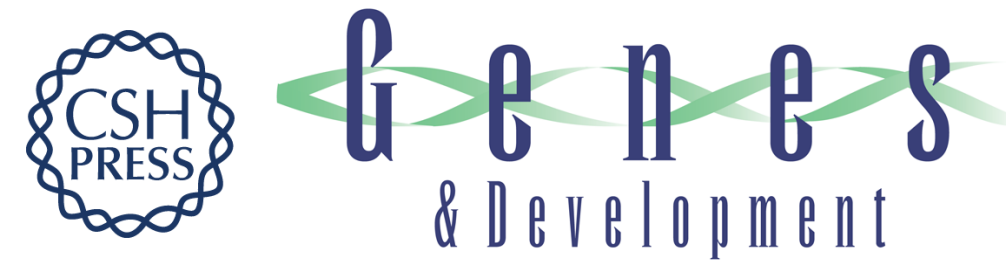

\section{Cellular survival: a play in three Akts}

Sandeep Robert Datta, Anne Brunet and Michael E. Greenberg

Genes Dev. 1999, 13:

References This article cites 233 articles, 124 of which can be accessed free at: http://genesdev.cshlp.org/content/13/22/2905.full.html\#ref-list-1

License

Email Alerting

Receive free email alerts when new articles cite this article - sign up in the box at the top Service right corner of the article or click here.

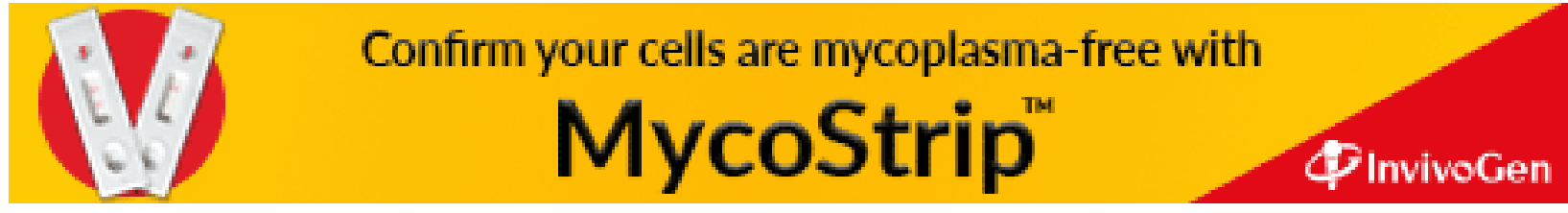

